\title{
Estudo correlacional entre configurações de iluminação ambiental versus percepção lumínica e térmica em câmara climática
}

\author{
Correlational study between daylighting configurations \\ and light and thermal perception in a climate chamber
}

\section{Cintia Akemi Tamura \\ Eduardo Leite Krüger}

Resu diferentes configurações de iluminação ambiente e variáveis subjetivas de percepção térmica e de iluminação. Realizaram-se testes em câmara climática giratória, localizada em Karlsruhe, Alemanha $\left(49^{\circ} \mathrm{N}, 8,5^{\circ} \mathrm{E}\right) .16$ indivíduos permaneceram sob condições térmicas controladas $(\mathrm{PMV} \pm 0,5)$ ao longo de $5 \mathrm{~h}$ (8h00 às 13h00 - horário local) por três estações do ano de 2015, totalizando nove dias de coleta por indivíduo, com 36 dias de experimentos no total. Levantaram-se variáveis objetivas com espectrorradiômetros e confortímetros. A percepção subjetiva das características de iluminação e de conforto térmico foi levantada por questionários. Correlacionaram-se estatisticamente (Spearman, rs) dados subjetivos com dados objetivos ambientais: iluminância (E - lux), temperatura de cor aparente (TCC - K), comprimento de onda dominante (DWl - nm) e fator de ação circadiano $\left(\mathrm{a}_{\mathrm{cv}}\right)$ para a amostra total e para o grupo dos indivíduos com cronotipo indiferente $(\mathrm{n}=11)$. Observaram-se correlações significativas apenas entre a percepção de temperatura e as variáveis ambientais em situações com menor disponibilidade de luz natural (inverno, fachada não equatorial) para os dois grupos avaliados, sendo as correlações maiores para o grupo cronotipo indiferente.

Palavras-chave: Iluminação. Câmara climática. Fator de ação circadiano. Percepção lumínica. Percepção térmica.

\begin{abstract}
Human interactions in the built environment are mediated by physiological and psychological stimuli, which may interfere in the perception of environmental comfort variables. In this context, the degree of correlation between different ambient lighting configurations in terms of subjective thermal and light perception was evaluated. Tests were carried out in a rotating climatic chamber, located in Karlsruhe, Germany $\left(49^{\circ} N, 8,5^{\circ} \mathrm{E}\right) .16$ subjects remained under controlled thermal conditions (PMV \pm 0.5) over 5 h (8:00 a.m. to 1:00 p.m. local time) during three seasons in 2015, totalizing nine days of collection per individual, with 36 experimental sessions in total. Objective variables were assessed with spectroradiometers and comfort meters. Subjective perception of lighting characteristics and thermal comfort was obtained from questionnaires. (DWl-nm), and circadian action factor $\left(a_{c v}\right)$ were correlated statistically (Spearman, rs) with objective environmental data: for the whole sample and for the group of individuals with indifferent chronotype $(n=11)$. Significant correlations were observed only between temperature perception and environmental variables in situations with less available natural light (winter, non equatorial façade) for the two groups evaluated, and the correlations were higher for the indifferent chronotype group.
\end{abstract}

Cintia Akemi Tamura Universidade Tecnológica Federal do
Paraná Curitiba - PR - Brasil

Eduardo Leite Krüger

Curitiba - PR - Brasil

Recebido em 09/11/17 Aceito em 07/02/18

Keywords: Lighting. Climate chamber. Circadian action factor. Light perception. Thermal perception.

TAMURA, C. A.; KRÜGER, E. L. Estudo correlacional entre configurações de iluminação ambiental versus percepção lumínica e térmica em câmara climática. Ambiente Construído, Porto Alegre, v. 18, n. 3, p. 97-117, jul./ set. 2018. ISSN 1678-8621 Associação Nacional de Tecnologia do Ambiente Construído. 


\section{Introdução}

Percepção e preferências de humanos quanto à iluminação ambiental para a obtenção de conforto visual variam conforme as características da fonte luminosa. Tais impressões, por sua vez, podem ser influenciadas por características individuais como a idade (ZHONG et al., 2017), o sexo (CHELLAPPA et al., 2017) e a personalidade (DESPENIC et al., 2017).

Ademais, o uso dos ambientes em que a luz se manifesta também pode influenciar diretamente na satisfação e preferência dos indivíduos quanto à iluminação, como escritórios (FARIA; INSKAVA; PLANITZER, 2017), museus (KAYA; AFACAN, 2017), hospitais (STIDSEN; BJERRUM; KIRKEGAARD, 2011) ou espaços educacionais (BARKMANN; WESSOLOWSKI; SCHULTEMARKWORT, 2012).

Apesar da complexidade do assunto, é conhecido e amplamente documentado o impacto que diferentes condições de iluminação de um ambiente podem ter na obtenção de conforto visual durante a execução de tarefas visuais (SILVESTER; KONSTANTINOU, 2010; BEUTE; DE KORT, 2013).

No entanto, estudos mostram a influência da luz também em respostas não visuais, mediadas pelo principal órgão do sistema visual, os olhos. Dependendo de fatores como a presença ou não da iluminação, de sua intensidade e composição espectral, esta pode ter impactos em diversos aspectos, como o ciclo sono-vigília (CAJOCHEN, 2007), estados de humor (HUBALEK; BRINK; SCHIERZ, 2010) e a saúde física e mental (GALASIU; VEITCH, 2006; EAGLES, 2009; KARATSOREOS, 2012). Cabe ressaltar o atual reconhecimento pela comunidade científica acerca da relevância dos impactos não visuais da iluminação em humanos. Em 2016, a Commission Internationale de L'Eclairage (COMMISSION..., 2016) incluiu o tema como o primeiro na lista de tópicos a serem urgentemente explorados em pesquisas no campo da iluminação.

No mesmo âmbito, Kulve et al. (2016) corroboram a possibilidade de que a luz também seja capaz de suscitar respostas fisiológicas não ligadas somente à percepção visual, mas também à percepção térmica. Para isso, realizaram extensa revisão bibliográfica, que resultou em um limitado conjunto de pesquisas que relacionam a intensidade e a cor da luz com a termorregulação humana. Também discorrem sobre a ação do efeito psicológico baseado na ligação entre a cor e a intensidade da luz e como esses aspectos podem estar associados à sensação de calor ou frio. Dessa forma, as inter- relações entre informação visual e termofisiológica permanecem ainda não claramente compreendidas (KULVE et al., 2016).

Algumas das características intrínsecas da iluminação que podem influenciar em aspectos não relacionados à visão em humanos são a temperatura de cor correlata (TCC), o comprimento de onda dominante (DWl) e o fator de ação circadiano $\left(\mathrm{a}_{\mathrm{cv}}\right)$. Este último, representado por um valor adimensional, indica a eficácia da luz em contribuir com a regularização do ciclo circadiano. O valor de referência adotado no trabalho é o da incidência solar direta, $\mathrm{a}_{\mathrm{cv}}=0,76$ (GALL et al., 2004).

Pesquisas ligam valores distintos de TCC a alterações no estado de alerta e no desempenho cognitivo. Em estudo com 16 indivíduos, Chellappa et al. (2011) verificaram que a exposição de homens à luz de três diferentes fontes artificiais (lâmpadas fluorescentes compactas com iluminância de 40 lux e temperatura de cor correlata de $6.500 \mathrm{~K}$ e 2.500 $\mathrm{K}$, e lâmpadas incandescentes com iluminância de 40 lux e temperatura de cor correlata de $3.000 \mathrm{~K}$ ), durante $2 \mathrm{~h}$ à noite, produziram diferentes resultados nessas variáveis. A exposição à luz com $6.500 \mathrm{~K}$ (cor fria) levou a uma maior supressão da melatonina, particularmente $90 \mathrm{~min}$ após a exposição, e aumentou o alerta subjetivo. Com relação ao desempenho cognitivo, a luz em $6.500 \mathrm{~K}$ levou a tempos de reação significativamente mais rápidos em tarefas associadas à atenção, mas não em tarefas associadas à função executiva. Essa melhora cognitiva esteve fortemente relacionada com a diminuição dos níveis de melatonina salivar, particularmente para essa condição (CHELLAPA et al., 2011).

Outra correlação relatada em pesquisas é a influência que a TCC pode ter na percepção da temperatura do ambiente. Essa relação é descrita pela teoria de matiz-calor (Hue-Heat Hypothesis $\mathrm{HHH}$ ), que sustenta que a luz com comprimentos de onda predominantemente na extremidade vermelha do espectro visível é sentida como quente, e que a luz predominantemente da extremidade azul é percebida como fria (HUEBNER et al., 2014). Apoiados nessa teoria, Nakamura e Oki (2000) realizaram experimentos em laboratório localizado em Ashikaga, no Japão, com controle de temperatura em duas situações ( $n=8$, homens). Na primeira, simulando o período de inverno, a temperatura foi mantida constante a $10^{\circ} \mathrm{C}$, e a TCC da iluminação variou entre $3.700 \mathrm{~K}, 5.500 \mathrm{~K}$ e 7.000 $\mathrm{K}$, sendo a TCC mais baixa (sensação quente) a preferida pelos indivíduos. Na segunda situação, simulando o período de verão, a temperatura do ar foi mantida em $30{ }^{\circ} \mathrm{C}$, e a TCC também variou, 
sendo a de valor mais alto (sensação fria) considerada a mais agradável pelos indivíduos.

Quanto ao DWl, estudos têm demonstrado que a supressão da melatonina é mais sensível à luz de comprimento de onda mais curto, sendo que há predominância da faixa azul do espectro como a mais eficaz para a manutenção das funções circadianas. Dois extensos estudos demonstraram que a luz com um pico de comprimento de onda entre $430 \mathrm{~nm}$ e $500 \mathrm{~nm}$ (azul) foi mais eficaz na supressão da melatonina noturna do que os comprimentos de onda mais longos (BRAINARD et al., 2001; THAPAN; ARENDT; SKENE, 2001).

Esses achados são reforçados pelos obtidos por Anderson et al. (2009), em experimento com mulheres adultas $(n=12)$. Esse trabalho contrariou a recomendação até então estabelecida de exposição a 3.000-5.000 lux-h/dia para tratamento do transtorno afetivo sazonal leve, prevista na literatura clínica. As pacientes, que foram submetidas a fontes de luz com iluminância média de 98 a 700 lux (mas emitiam um número equivalente de fótons dentro do intervalo de comprimento de onda curto) por $45 \mathrm{~min} / \mathrm{dia}$, demonstraram altas taxas de remissão ao longo de 3 semanas de tratamento. Dessa forma, tomar somente valores de iluminância como padrão para a dose terapêutica de tratamento desse transtorno é inadequado, sendo necessária atenção especial ao espectro do comprimento de onda predominante da fonte de luz.

Em relação ao fator de ação circadiano, Gall et al. (2004) demonstraram que este possui correlação direta com o TCC, sendo a correlação $\left(\mathrm{R}^{2}\right)$ para as duas variáveis da ordem de 0,9744 . Isso equivale a afirmar que, quanto mais fria a temperatura aparente da luz, maior será sua efetividade circadiana. Os mesmos autores demonstram que o $\mathrm{a}_{\mathrm{cv}}$ também possui relação conhecida com o espectro dominante - DWl (nm) -, sendo esta inversamente proporcional. Nesse caso, quanto maior o valor de nm, menor será seu potencial de regularização do ciclo circadiano.

Nesse contexto, como forma de contribuir e ampliar o campo de estudo, o presente trabalho foca nos possíveis impactos de diferentes configurações oriundas de fontes de luz diversas na percepção lumínica e na sensação térmica de humanos.

O trabalho teve por objetivo levantar, descrever e correlacionar estatisticamente variáveis objetivas advindas de diferentes condições de iluminação ambiental com variáveis subjetivas relacionadas à

${ }^{1}$ Departamento de Física e Tecnologia das Edificações. 2 Maiores detalhes em Schweiker et al. (2014). percepção térmica e luminosa de indivíduos em ambientes-teste de uma câmara climática giratória.

\section{Método}

As etapas de realização da pesquisa apoiaram-se nos seguintes procedimentos:

(a) definição das configurações de iluminação dos ambientes-teste e protocolos aplicados aos participantes;

(b) descrição das variáveis objetivas monitoradas e equipamentos utilizados;

(c) caracterização da amostra e definição das variáveis subjetivas avaliadas e ferramentas de mensuração;

(d) apresentação dos resultados;

(e) discussão dos resultados; e

(f) conclusões.

\section{Caracterização dos ambientes-teste e configurações gerais}

\section{Câmara climática Lobster}

Os ensaios com diferentes configurações de iluminação foram realizados no Laboratory for Occupant Behaviour, Satisfaction, Thermal Comfort and Environmental Research (Lobster), em câmara climática giratória de propriedade do Karlsruher Institut für Technologie, localizado em Karlsruhe, na Alemanha $\left(49^{\circ} \mathrm{N}, 8,5^{\circ} \mathrm{L}\right)$. Desenvolvido pelo Fachgebiet Bauphysik \& Technischer Ausbau ${ }^{1}$ (fbta/KIT), o Lobster é composto de dois ambientes-teste com aproximadamente $23 \mathrm{~m}^{2}$ cada, configurados e mobiliados à maneira de escritórios, e com capacidade para receber até dois indivíduos simultaneamente. No interior desses ambientesteste, variáveis ambientais podem ser initerruptamente monitoradas e/ou controladas. As variáveis climáticas, por sua vez, são continuamente registradas por uma estação meteorológica localizada na cobertura da câmara. ${ }^{2}$

Cada ambiente-teste tem uma fachada envidraçada, com $\mathrm{WWR}^{3}=73 \%$. As janelas operáveis têm painel triplo com VLT (visible light transmittance) de 70, e as janelas fixas, VLT 72. A Tabela 1 apresenta sinteticamente áreas e proporções entre janelas, aberturas envidraçadas e piso de um ambiente-teste.

A fachada envidraçada da câmara climática Lobster pode ser orientada para diversas posições cardeais graças ao trilho circular em que o conjunto se

${ }^{3} \mathrm{O}$ WWR (window to wall ratio) é a relação em porcentagem entre a área da abertura envidraçada e a área da parede na qual ela se encontra. 
sustém, o que possibilita giros de até $355^{\circ}$. A Figura 1 apresenta a planta humanizada e a fachada envidraçada da câmara.

\section{Configurações adotadas para os ambientes- teste}

As campanhas para coleta de dados foram realizadas ao longo de três estações: inverno, primavera e verão de 2015. Cada estação contou com 12 dias de testes, que foram selecionados tendo em vista a maior proximidade possível com a data de equinócio ou solstício em cada estação, totalizando 36 dias.

Em todas as estações foram testadas três configurações de iluminação:

(a) orientação da fachada com janela para S/SO

$\left(200^{\circ} / 255^{\circ} \text { - orientação equatorial }\right)^{4}$;

(b) orientação de fachada envidraçada para N/NO

(335 - orientação não equatorial); e

(c) persiana externa fechada e fonte de luz elétrica.
Adicionalmente, registraram-se as condições climáticas diárias. As duas orientações de fachada, equatorial (Eq) e não equatorial (Neq), foram definidas após a realização de simulações computacionais de iluminação natural (WEISS; KRÜGER; TAMURA, 2015), que identificaram as condições que apresentariam máxima diferenciação entre possibilidades de acesso à luz natural, porém sem ofuscamento direto no campo de trabalho.

Nos dias em que a fonte de iluminação foi exclusivamente elétrica (Elét), utilizaram-se quatro lâmpadas fluorescentes Osram L36W/840 (TCC=4.000 K e IRC>80) (OSRAM, 2018), índices classificados como satisfatórios para atividades gerais de escritório, conforme a norma DIN 6169-2 (1976). As luminárias foram direcionadas para o teto, e as paredes e teto eram da cor branca, resultando em luz difusa no plano de trabalho, com Eméd no plano de trabalho de 1.500 lux. O Quadro 1 apresenta as configurações adotadas para cada um dos 36 dias de testes, além da condição climática prevalente em cada data.

Tabela 1 - Áreas e proporções de cada ambiente-teste

\begin{tabular}{|c|c|c|}
\hline Superfície & Área $\left(\mathbf{m}^{2}\right)$ & Proporções \\
\hline Piso & 23,23 & $\mathrm{WFR}^{5}=35 \%$ \\
\hline Parede onde se localiza o envidraçado & 11,67 & \multirow{3}{*}{$\mathrm{WWR}^{6}=73 \%$} \\
\hline \multirow{2}{*}{ Área envidraçada } & Fixa $\left(4,9 \mathrm{~m}^{2}\right)-$ VLT 72 & \\
\hline & Operável $(3,7$ m²) - VLT 70 & \\
\hline
\end{tabular}

Figura 1 - Detalhamento da câmara climática Lobster

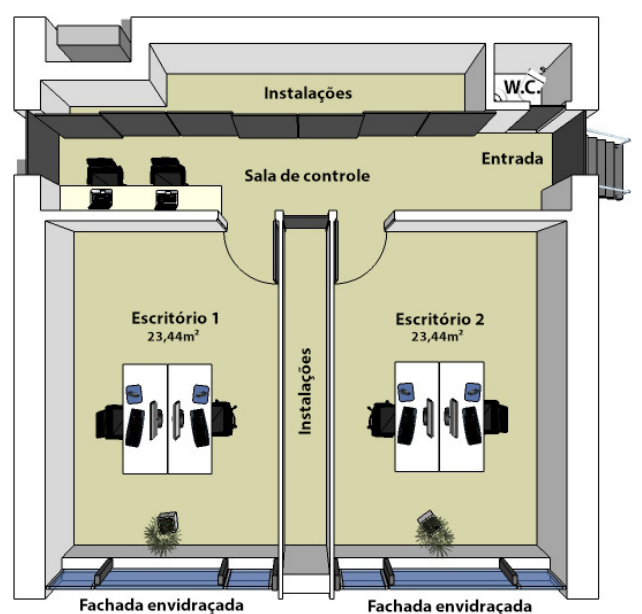

(a) Planta humanizada

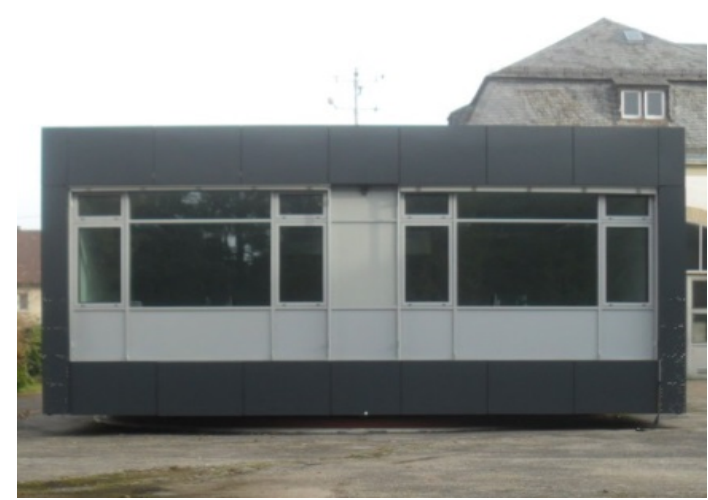

(b) Vista da fachada envidraçada

${ }^{4}$ Adota-se a referência da linha do equador para definir a fachada mais ensolarada. Dessa forma, uma orientação equatorial no hemisfério norte seria tipicamente voltada para 0 sul, e o inverso se aplicando ao hemisfério sul.

${ }^{5} \mathrm{O}$ WFR (window to flow ratio) corresponde à relação em porcentagem entre a área da abertura envidraçada e a área do piso do ambiente.

${ }^{6} O$ WWR (window to wall ratio) é a relação em porcentagem entre a área da abertura envidraçada e a área da parede na qual ela se encontra. 
Quadro 1 - Orientação da fachada envidraçada e condições climáticas observadas nos dias de teste com iluminação Eq e Neq para inverno, primavera e verão

\begin{tabular}{|c|c|c|c|c|c|c|c|c|c|c|c|c|}
\hline \multicolumn{13}{|c|}{ Inverno } \\
\hline Dia & 1 & 2 & 3 & 4 & 5 & 6 & 7 & 8 & 9 & 10 & 11 & 12 \\
\hline Iluminação* & $\mathrm{Eq}$ & Elét & Neq & Elét & $\mathrm{Neq}$ & $\mathrm{Eq}$ & $\mathrm{Eq}$ & $\mathrm{Neq}$ & Elét & $\mathrm{Neq}$ & Eq & Elét \\
\hline $\begin{array}{c}\text { Condições } \\
\text { de céu }\end{array}$ & A & N/A ${ }^{* *}$ & $\mathrm{C}$ & $\mathrm{N} / \mathrm{A}^{* *}$ & $\mathrm{C}$ & $\mathrm{C}$ & A & $\mathrm{C}$ & $\mathrm{N} / \mathrm{A}^{* *}$ & A & $\mathrm{C}$ & $\mathrm{N} / \mathrm{A}^{* *}$ \\
\hline \multicolumn{13}{|c|}{ Primavera } \\
\hline Dia & 13 & 14 & 15 & 16 & 17 & 18 & 19 & 20 & 21 & 22 & 23 & 24 \\
\hline Iluminação* & $\mathrm{Eq}$ & Elét & Neq & $\mathrm{Neq}$ & $\mathrm{Eq}$ & Elét & $\mathrm{Eq}$ & $\mathrm{Neq}$ & Elét & Elét & $\mathrm{Neq}$ & $\mathrm{Eq}$ \\
\hline $\begin{array}{c}\text { Condições } \\
\text { de céu }\end{array}$ & B & N/A** & A & A & A & N/A ${ }^{* *}$ & A & A & $\mathrm{N} / \mathrm{A}^{* *}$ & N/A* & B & B \\
\hline \multicolumn{13}{|c|}{ Verão } \\
\hline Dia & 25 & 26 & 27 & 28 & 29 & 30 & 31 & 32 & 33 & 34 & 35 & 36 \\
\hline Iluminação* & Elét & $\mathrm{Eq}$ & $\mathrm{Neq}$ & $\mathrm{Neq}$ & Elét & $\mathrm{Eq}$ & $\mathrm{Eq}$ & Elét & $\mathrm{Neq}$ & $\mathrm{Neq}$ & $\mathrm{Eq}$ & Elét \\
\hline $\begin{array}{c}\text { Condições } \\
\text { de céu }\end{array}$ & $\mathrm{N} / \mathrm{A}^{* *}$ & B & A & A & $\mathrm{N} / \mathrm{A}^{* *}$ & A & A & $\mathrm{N} / \mathrm{A}^{* *}$ & $\mathrm{C}$ & $\mathrm{C}$ & A & $\mathrm{N} / \mathrm{A}^{* *}$ \\
\hline
\end{tabular}

*Eq = iluminação equatorial;

Neq = iluminação não equatorial; e

Elét = iluminação elétrica.

** Nos dias em que se utilizou exclusivamente a iluminação elétrica, a condição climática tornou-se uma informação não aplicável (N/A).

$\mathrm{A}=$ Claro;

$\mathrm{B}=$ parcialmente encoberto; $\mathrm{e}$

$\mathrm{C}=$ totalmente encoberto.

O céu típico da localidade é o encoberto, frequente em regiões a altas latitudes. A disponibilidade de luz natural, por sua vez, é variável conforme a estação do ano. Apresenta dias curtos durante o período de inverno, com nascer do sol tardio. No verão, o sol nasce mais cedo e se põe mais tarde.

Quanto à configuração padrão para os dias de experimento, a Figura 2 ilustra os ambientes-teste juntamente com o posicionamento dos participantes em seus postos de trabalho para (a) iluminação natural (Eq e Neq) e (b) situação com luz elétrica (Elét).

\section{Configurações adotadas para a amostra}

Cada ambiente-teste recebeu simultaneamente dois indivíduos, que permaneceram em seu interior por 5 h (8h00-13h00, horário local), 3 dias a cada estação, totalizando 9 dias de coleta de dados por indivíduo. Todos utilizaram vestimenta padrão, composta de jeans, camiseta de manga curta e tênis, a fim de se minimizarem possíveis variações térmicas. Durante o período de experimento, controlou-se a ingestão de alimentos - substâncias com reconhecido potencial de influência no bemestar, como cafeína ou glicose, foram significativamente reduzidas. Disponibilizaram-se alimentos neutros como água sem gás, torradas, bolachas de maisena e frutas como pera e maçã. Vetaram-se alterações nas configurações predefinidas no ambiente, como abertura de janelas, acionamento de ventiladores ou movimentação das persianas externas. Além disso, os participantes foram orientados a não utilizar notebooks, smartphones ou quaisquer equipamentos que emitissem luz e pudessem alterar as configurações de iluminação preestabelecidas. Pelo mesmo motivo, uniformizaram-se as configurações de brilho dos monitores. Na necessidade de ausentarse dos ambientes-teste, como para a utilização do toalete fora da câmara, era solicitada a utilização de óculos escuros com proteção UV, que foram fornecidos pelos pesquisadores, para minimizar possíveis variações na intensidade e na fonte luminosa. Registrou-se em um diário todos os períodos em que os indivíduos eventualmente abriram a porta ou ausentaram-se dos ambientesteste. Posteriormente, os dados coletados durante esses períodos foram retirados das análises.

\section{Variáveis ambientais monitoradas e equipamentos utilizados}

As variáveis ambientais de iluminação monitoradas ao longo dos dias de experimento foram a iluminância (E), a temperatura correlata de cor (TCC), o comprimento de onda dominante (DWl) e o fator de ação circadiano $\left(\mathrm{a}_{\mathrm{cv}}\right)$. Como indicador do conforto térmico, calculou-se continuamente $\mathbf{0}$ PMV (predicted mean vote, ou voto médio predito), a partir dos dados de temperatura e umidade do ar, movimento do ar e temperatura radiante média, medidos nos ambientes. 
Figura 2 - Configurações de ambiente utilizadas

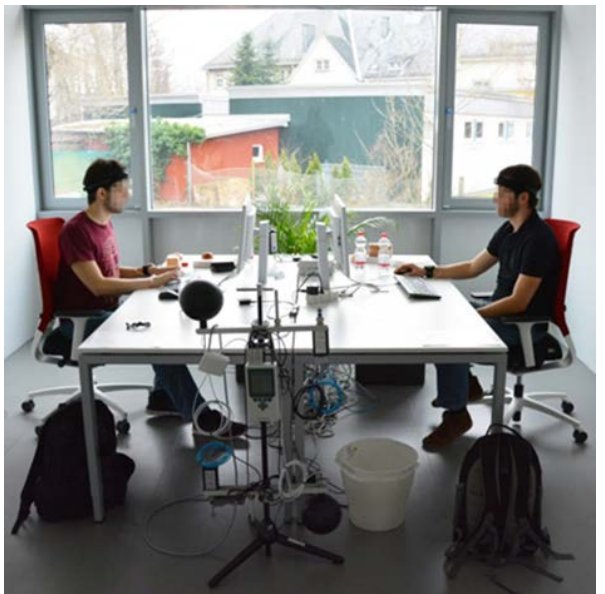

(a) Iluminação natural (Eq e Neq): janelas (vidro) cerradas sem uso de persiana externa

A iluminância (E), dada em lux, corresponde ao fluxo luminoso $(\varphi)$ incidente numa superfície por unidade de área $\left(\mathrm{m}^{2}\right)$. Como o fluxo luminoso não é distribuído uniformemente, E não será a mesma em todos os pontos de um ambiente; assim, utiliza-se frequentemente a $\mathrm{E}_{\text {méd }}$ (ELETROBRÁS; PROCEL, 2011). No estudo, adotou-se o valor mínimo de 500 lux como referência, conforme indicado para escritórios pela norma alemã DIN 5034 (DEUTSCHES..., 1997). Ainda que apenas as condições não relacionadas à visão sejam objeto de estudo do trabalho, a iluminância foi incluída no rol de variáveis avaliadas a fim de se verificar se esta poderia influenciar a percepção térmica.

A temperatura correlata de cor (TCC) é uma especificação para fontes de luz branca, utilizada para descrever seu tom de cor dominante, juntamente com a dimensão de quente (amarelo e vermelho) e frio (azul). Fontes de luz com uma classificação de TCC abaixo de 3.200 K são normalmente consideradas de aparência aquecida, enquanto aquelas com uma TCC acima de $5.000 \mathrm{~K}$ são normalmente consideradas frias na aparência. Temperaturas intermediárias são consideradas neutras (ELETROBRÁS; PROCEL, 2011).

O comprimento de onda dominante (DWl), dado em nanômetros (nm), está relacionado ao espectro eletromagnético predominante da luz, influenciando diretamente sua cor. A luz visível abrange a região entre $380 \mathrm{~nm}$ (violeta) e $770 \mathrm{~nm}$ (vermelho) (ELETROBRÁS; PROCEL, 2011).

O fator de ação circadiano $\left(\mathrm{a}_{\mathrm{cv}}\right)$ é uma métrica proposta pela DIN (DEUTSCHES..., 2009) que possibilita a determinação do efeito circadiano de diferentes fontes de luz em humanos (DIETRICH; BIESKE, 2004). Valores maiores indicam maior

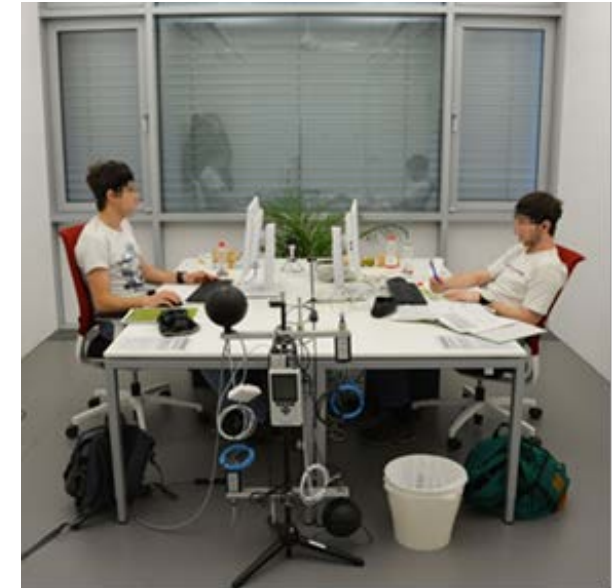

(b) Iluminação elétrica (Elét): janelas (vidro) cerradas e persiana externa em uso

efetividade da luz em contribuir para a regulação do ciclo circadiano, juntamente com fatores como:

(a) iluminância que incide diretamente nos olhos;

(b) espectro de cor da luz;

(c) direção da luz; e

(d) dinamismo desta (HRASKA, 2015).

$\mathrm{O}$ valor de $\mathrm{a}_{\mathrm{cv}}$ é dado pela Equação 1 .

$a_{c v}=\frac{\int_{380}^{580} X_{\lambda}(\lambda) \cdot c(\lambda) \cdot d(\lambda)}{\int_{380 n m}^{780 n m} X_{v \lambda}(\lambda) \cdot V(\lambda) \cdot d(\lambda)}$

Onde:

$\mathrm{X}_{\lambda}(\lambda)=$ distribuição espectral da radiação $(\mathrm{nm})$;

$\mathrm{C}(\lambda)=$ espectro de ação para a regulação da melatonina $(\mathrm{nm})$;

$\lambda 1, \lambda 2=$ comprimento de onda limite para ação do espectro (nm);

$\mathrm{X}_{\lambda}(\lambda)=$ distribuição espectral da radiação $(\mathrm{nm})$;

$\mathrm{X} \lambda(\lambda)=$ distribuição espectral da luz (nm); e

$\mathrm{V}(\lambda)=$ eficiência luminosa espectral para a visão fotóptica (nm).

Complementarmente, os valores de $\mathrm{a}_{\mathrm{cv}}$ resultantes de alguns tipos de fontes de luz são apresentados no Quadro 2. Por fim, o voto médio predito (PMV) é uma métrica proposta por Fanger (1973) que prediz a média das avaliações subjetivas quanto ao conforto térmico de pessoas em um ambiente. Estrutura-se em uma escala de sensação térmica de sete pontos, que varia de -3 (frio) a +3 (quente), sendo 0 a sensação de termicamente neutro. O PMV é um índice baseado em estados permanentes de transferência de calor e desenvolvido para ambientes internos, sendo utilizado para avaliação térmica de ambientes condicionados 
artificialmente, conforme a ISO 7730 (INTERNATIONAL..., 2005).

\section{Condições de iluminação na superfície de trabalho}

No monitoramento das variáveis objetivas de iluminação, iluminância (E - lux), temp. de cor
(TCC - K), comprimento de onda dominante (DW - $\mathrm{nm}$ ) e fator de ação circadiano $\left(\mathrm{a}_{\mathrm{cv}}\right)$, utilizaram-se dois espectrorradiômetros JETI modelo Specbos 1201 (Figura 3a), um em cada ambiente-teste. Os equipamentos foram posicionados na superfície de trabalho (mesas dos participantes, $\mathrm{h}=0,75 \mathrm{~m}$ ).

Quadro 2 - Dados compilados por Gall et al. (2004)7, 8 para valores de $\mathrm{a}_{\mathrm{cv}}$ de diversas fontes de luz (elétrica e natural)

\begin{tabular}{|l|c|}
\hline \multicolumn{1}{|c|}{ Fontes de luz } & Valor de acv \\
\hline Incidência solar direta $5.081 \mathrm{~K}$ & 0,76 \\
\hline Céu azul 19.963 K & 1,49 \\
\hline Céu nublado 5.924 K & 0,88 \\
\hline Lâmpada incandescente $2.800 \mathrm{~K}$ & 0,35 \\
\hline HMI 3.640 K, branco neutro, cerâmico & 0,39 \\
\hline Lâmpada de sódio de alta pressão 2.770 K & 0,28 \\
\hline Lâmpadas fluorescentes & Valor de $\mathbf{a}_{\mathbf{c v}}$ \\
\hline Branco quente $2.827 \mathrm{~K}$ & 0,31 \\
\hline Branco neutro 3.678 K & 0,52 \\
\hline BASIC Daylight 765 6.750 K & 0,85 \\
\hline LUMILUX Daylight $8656.400 \mathrm{~K}$ & 0,80 \\
\hline Deluxe Biolux 965 6.500 & 0,94 \\
\hline Lumilux Skywhite $8808.000 \mathrm{~K}$ & 1,00 \\
\hline “Truelite” 5.600 K & 0,76 \\
\hline Diodos emissores de luz & Valor de $\mathbf{a}_{\mathbf{c v}}$ \\
\hline Led blue $\lambda$ max=468 nm & 6,90 \\
\hline Led white & 1,05 a 2,00 \\
\hline máximo (monocromático $460 \mathrm{~nm}$ ) & 26,30 \\
\hline
\end{tabular}

Figura 3 - Equipamentos utilizados na coleta de dados ambientais

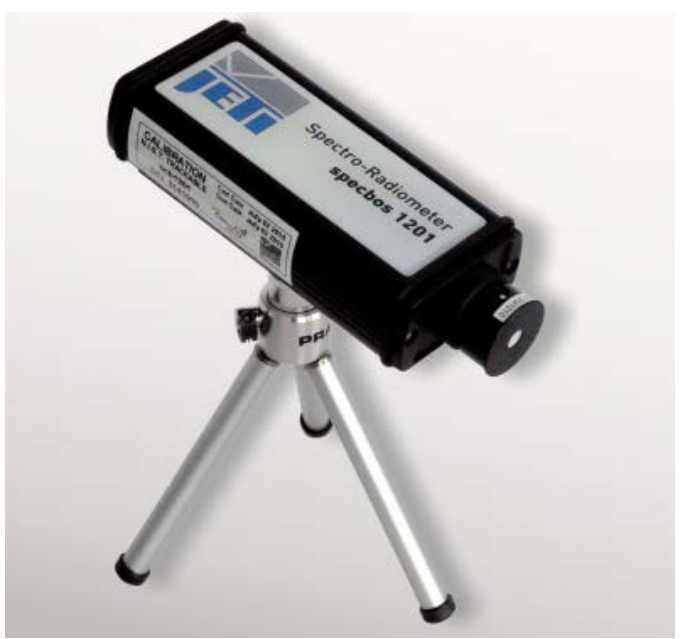

(a) Espectrorradiômetro JETI modelo Specbos 1201

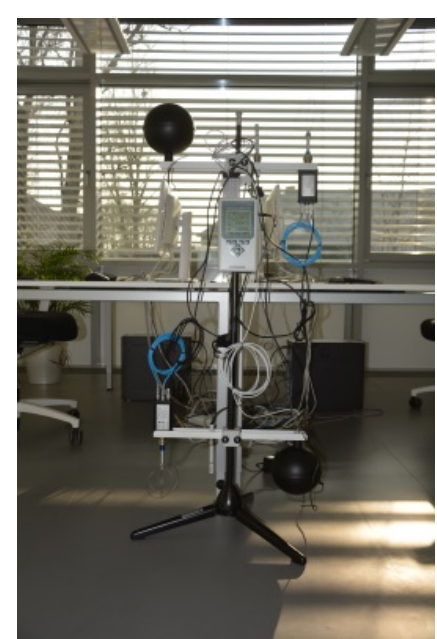

(b) Confortímetro AHLBORN modelo ALMEMO 2690

${ }^{7} \mathrm{GALL}$, D. et al. Die Ermittlung von Licht-und Farbfeldgrößen zur Bestimmung der spektralen Wirkung des Lichtes. Technische Universität Ilmenau, Fachgebiet Lichttechnik, 2004.

8OSRAM - Messungen Lichtlabor (2004). 
A frequência de coleta de dados foi configurada para $5 \mathrm{~min}$. Entretanto, dado o processo de integração realizado pelo equipamento, esse intervalo de tempo mostrou-se variável, oscilando entre $5 \mathrm{~min}$ a $7 \mathrm{~min}$. Por essa inconstância de registro, realizou-se posteriormente uma interpolação, de forma a se obterem valores com a frequência de $1 / 60 \mathrm{~s}$, que foram utilizados nesta pesquisa. As Figuras 4 a 7 apresentam a média dos resultados das variáveis objetivas relacionadas à iluminação registradas pelo espectrorradiômetro para os dois ambientes-teste, para as três condições de iluminação avaliadas: luz natural para fachada equatorial (Eq), não equatorial (Neq) e luz elétrica (Elét). São também indicados os valores máximos, médios e mínimos alcançados durante o período dos experimentos, quando aplicável, e para as $12 \mathrm{~h} 30$, horário de preenchimento dos questionários de percepção lumínica e térmica no ambiente.

Os resultados das variáveis objetivas de iluminação registradas para as três configurações adotadas mostraram alinhamento à literatura correlata. Valores maiores de E foram registrados para a iluminação Eq. Quanto à iluminação necessária para a execução de tarefas visuais, pode-se afirmar que os ambientes-teste mantiveram-se predominantemente na faixa de conforto $(>500$ lux), à exceção de períodos ao longo dos dias de inverno, quando o alvorecer ocorria após o início dos testes (8h00). Para situação de iluminação Elét, o valor permaneceu estável na faixa de 1.500 lux.

Quanto à TCC, os dias com iluminação Eq sempre registraram valores na faixa de $>6.000 \mathrm{~K}$, correspondente à cor fria (azul). Nos dias de iluminação Elét, registraram-se valores entre 3.880 $\mathrm{K}$ e $3.900 \mathrm{~K}$, correspondente à cor branca. Os valores de DWl acompanham essa característica; testes com iluminação natural concentraram valores entre $498 \mathrm{~nm}(\mathrm{Eq})$ e $491 \mathrm{~nm}(\mathrm{Neq})$, correspondentes ao comprimento de onda eletromagnética azul, mais adequado à ativação de funções circadianas (THORNE et al., 2009). Para iluminação Elét, a faixa manteve-se em $577 \mathrm{~nm}$ (amarelo).

Para a avaliação do fator de ação circadiano resultante de cada fonte de luz, considerou-se como valor de referência $a_{\mathrm{cv}}=0,76$, equivalente à incidência solar direta (GALL et al., 2004). O valor médio da métrica manteve-se maior em dias de iluminação natural $(\mathrm{Eq}=0,94$; Neq=0,98), e menor em dias de iluminação Elét $\left(\mathrm{a}_{\mathrm{cv}}=0,45\right)$. Verificou-se discreto aumento do fator para a fachada Neq, fato que se deveu à presença de maior provisão de céu desobstruído, posteriormente identificado para essa orientação cardeal. Como programado durante a fase de testes por meio de simulações para a escolha das orientações para a fachada envidraçada da câmara, houve eventuais manchas solares no interior dos ambientes-teste, mas nunca nos planos de trabalho.

\section{Condições de temperatura no interior dos ambientes-teste}

Objetivando-se excluir o efeito de variações térmicas na percepção dos indivíduos, as condições ambientais dos ambientes-teste foram programadas e continuamente monitoradas. Para isso se utilizaram confortímetros ALMEMO 2690 (Figura $3 \mathrm{~b}$ ), que registraram a intervalos de $10 \mathrm{~s}$ dados dos ambientes-teste como temperatura do ar ( $\left.\mathrm{Ta}-{ }^{\circ} \mathrm{C}\right)$, temperatura do globo $\left(\mathrm{Tg}-{ }^{\circ} \mathrm{C}\right)$, umidade relativa (RH - \%) e velocidade do ar ( $\left.\mathrm{V}_{\mathrm{ar}}-\mathrm{m} / \mathrm{s}\right)$.

A análise desses dados possibilitou a verificação de que os indivíduos foram expostos a condições térmicas estáveis no interior da câmara ao longo das 5 h de duração de cada sessão de testes.

Notou-se no geral uma fase de discreto aquecimento na primeira hora, porém sem alterações significativas no PMV ao longo das 4 h restantes. A Figura 8 apresenta os valores máximos, médios e mínimos, o desvio padrão e a média do PMV para os dois ambientes-teste registrados ao longo dos dias de testes. É também indicado o valor médio do índice às 12h30, horário de preenchimento dos questionários subjetivos de percepção de iluminação e conforto térmico (ponto preto). Nesse horário, o valor médio esteve predominantemente próximo à condição térmica de neutralidade $(\mathrm{PMV}=0)$, entre aproximadamente $-0,2 \mathrm{e}+0,3$. 
Figura 4 - Iluminância média (Eméd. - lux) dos dois escritórios-teste registrados ao longo dos dias de teste para as três estações, para dias com: (a) iluminação natural, Eq; (b) iluminação natural, Neq; e (c) iluminação Elét, e indicação do valor de Eméd. às $12 \mathrm{~h} 30$

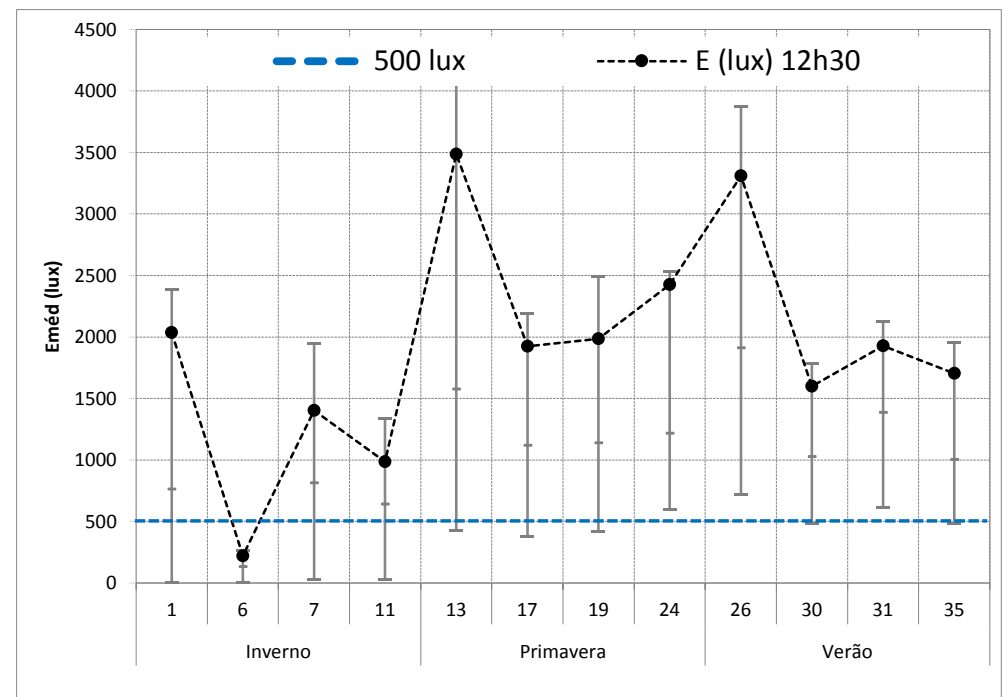

(a)

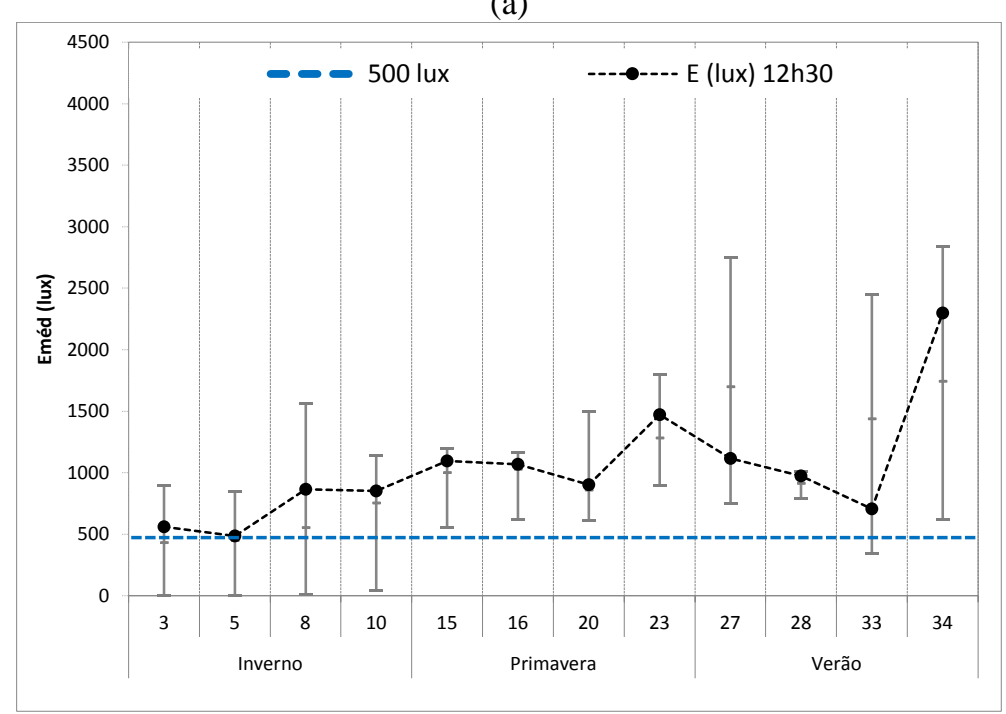

(b)

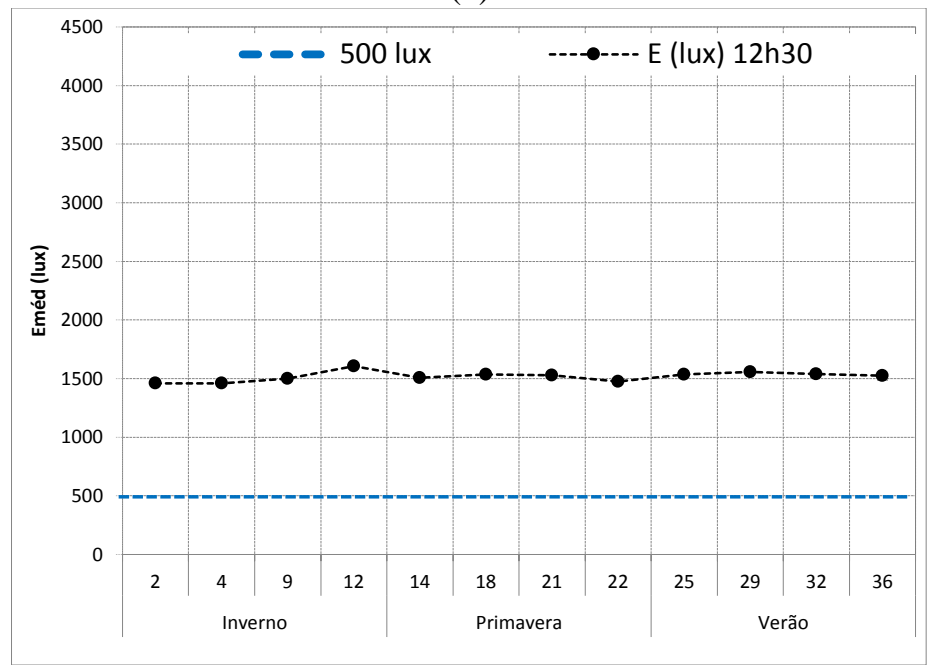

(c) 
Figura 5 - Temperatura de cor média (TCC méd. - K) dos dois escritórios-teste registrados ao longo dos dias de teste para as três estações, para dias com: (a) iluminação natural, Eq; (b) iluminação natural, Neq; e (c) iluminação Elét, e indicação do valor de TCC méd. às $12 \mathrm{~h} 30$

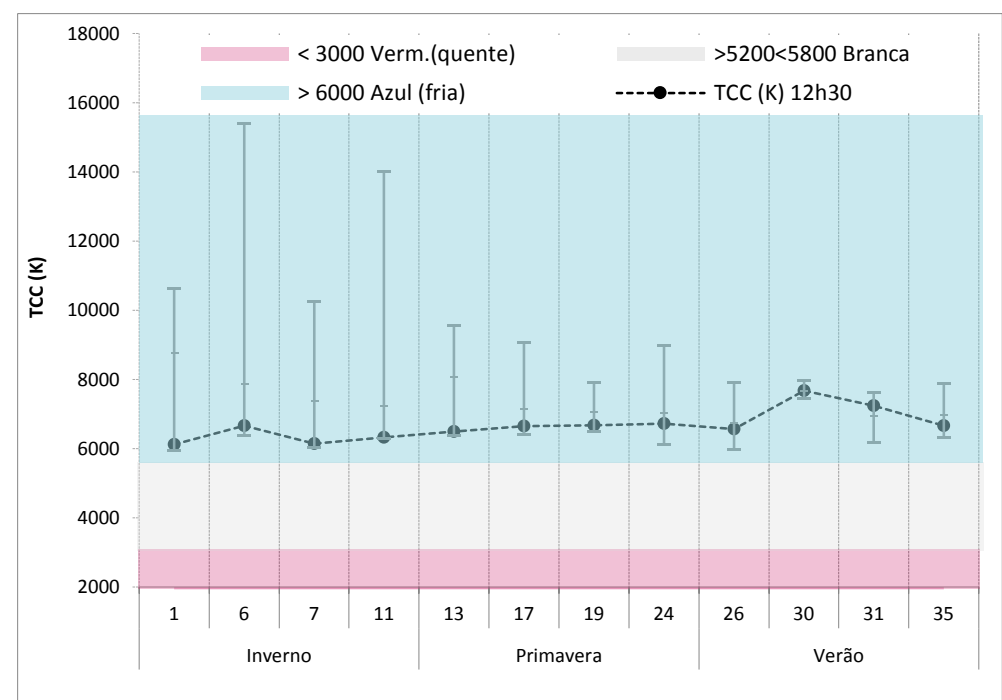

(a)

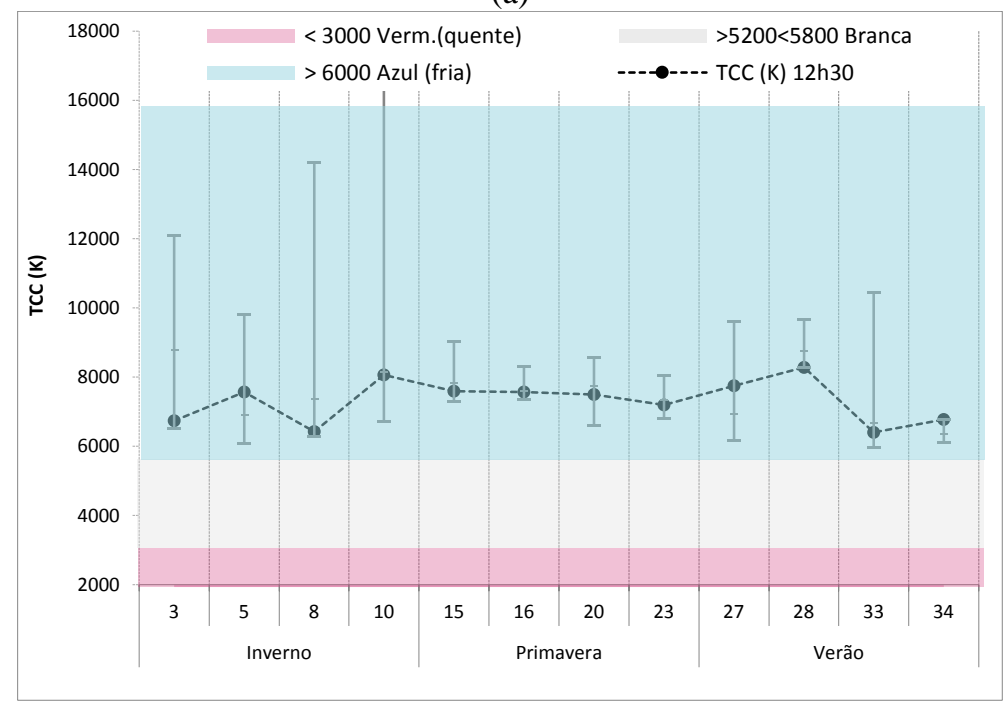

(b)

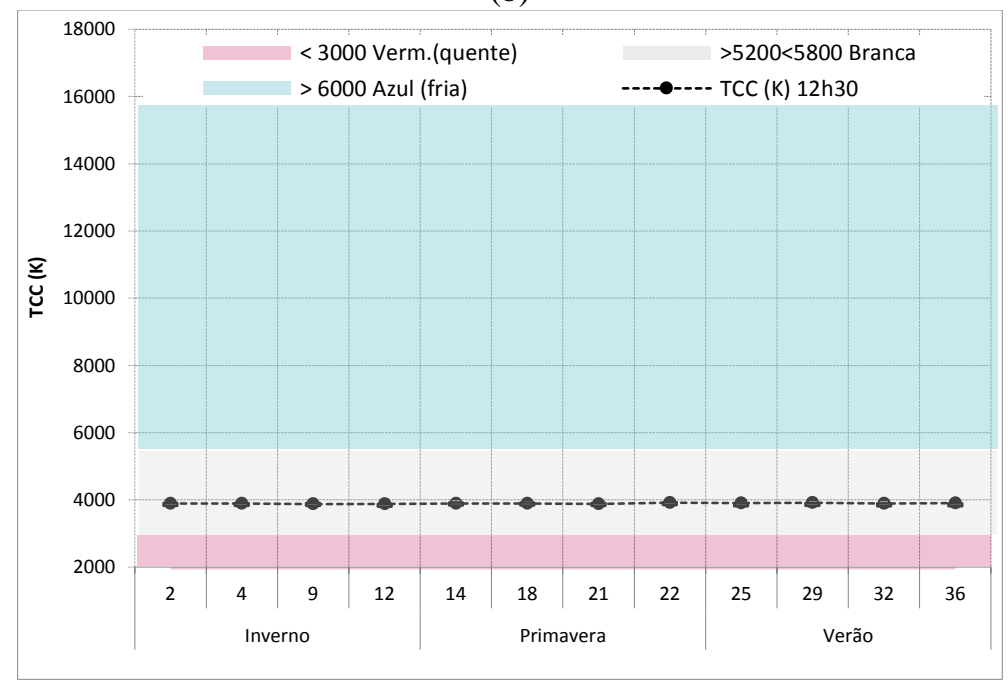

(c) 
Figura 6 - Comprimento de onda média (DWI méd. - $\mathrm{nm}$ ) dos dois escritórios-teste registrados ao longo dos dias de teste para as três estações, para dias com: (a) iluminação natural, Eq; (b) iluminação natural, Neq; e (c) iluminação Elét, e indicação do valor de DWI méd. às 12 h30

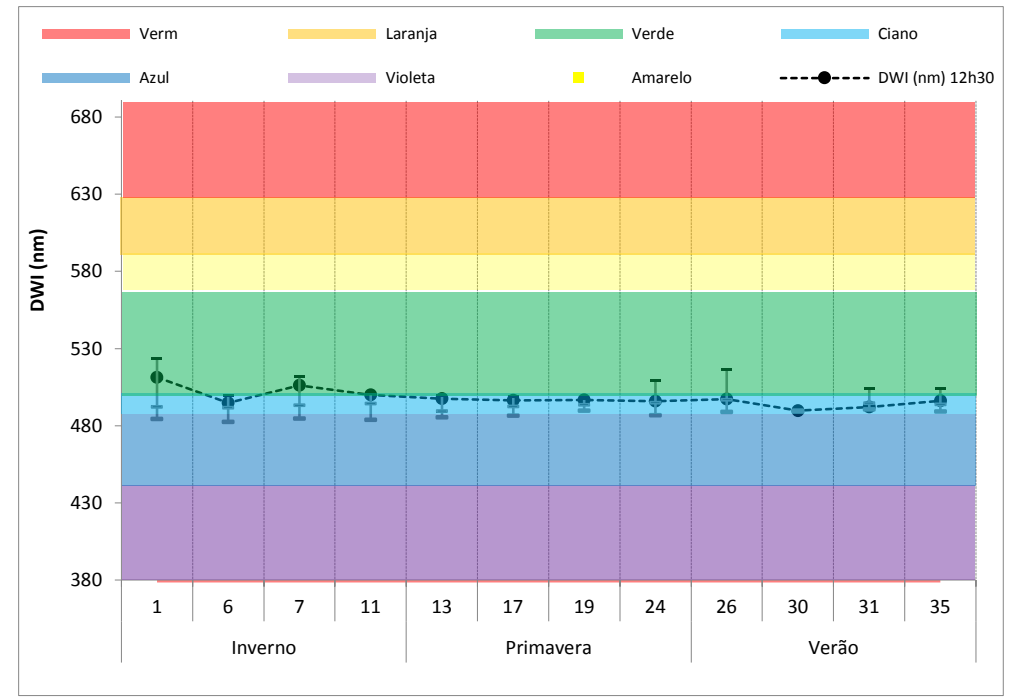

(a)

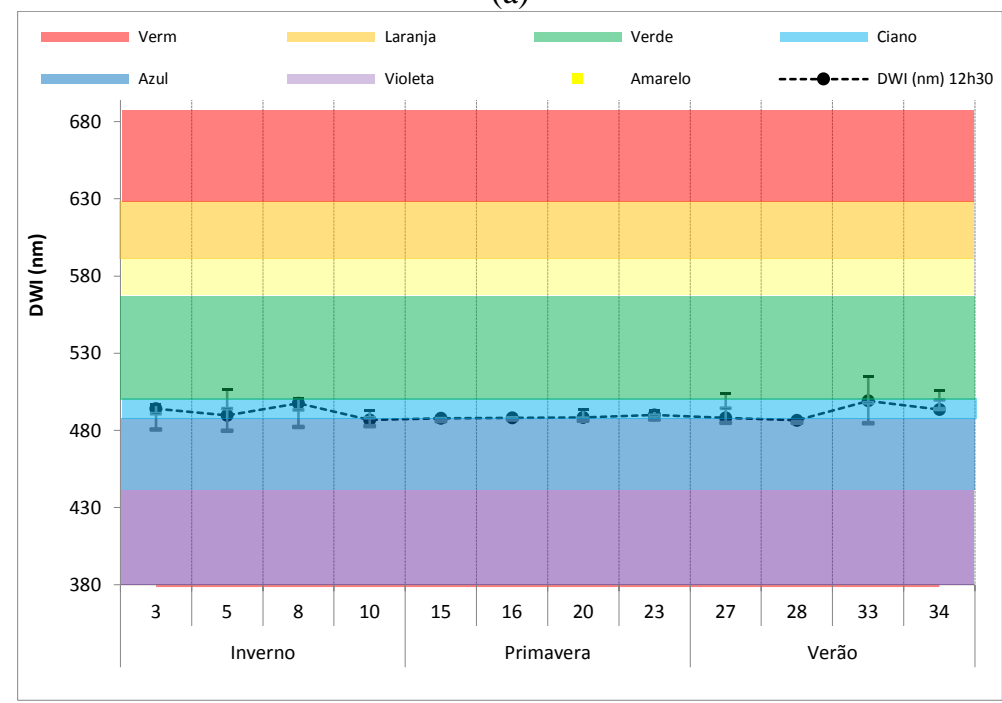

(b)

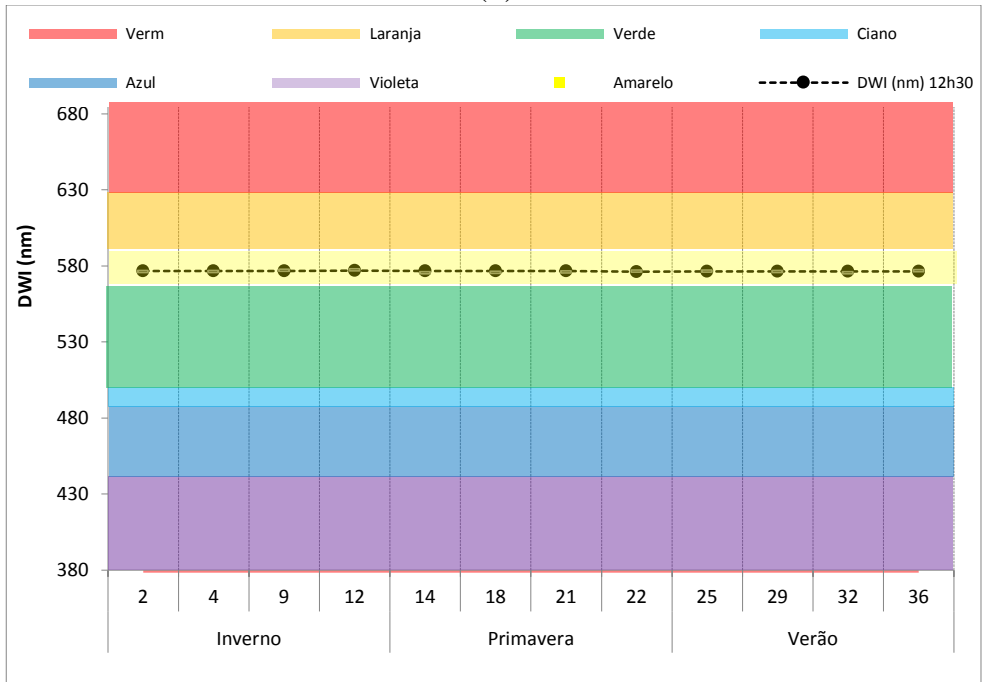

(c) 
Figura 7 - Fator de ação circadiano ( $\mathrm{a}_{\mathrm{cv}}$ méd.) dos dois escritórios-teste registrados ao longo dos dias de teste para as três estações, para dias com: (a) iluminação natural, Eq; (b) iluminação natural, orientação Neq; e (c) iluminação Elét, e indicação do valor de $a_{c v}$ méd. às $12 \mathrm{~h} 30$

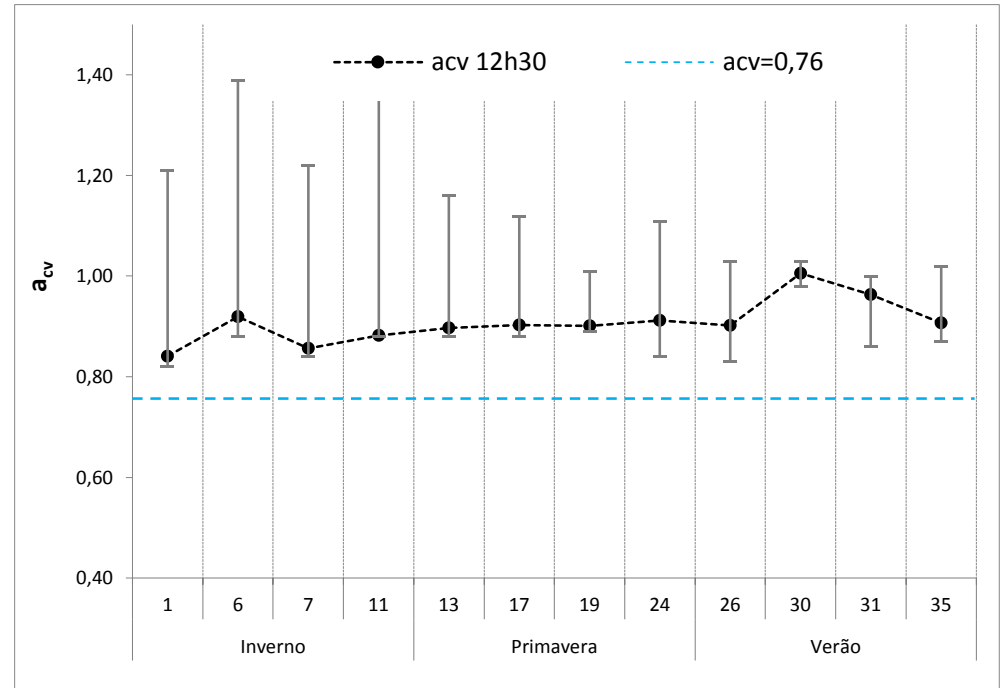

(a)

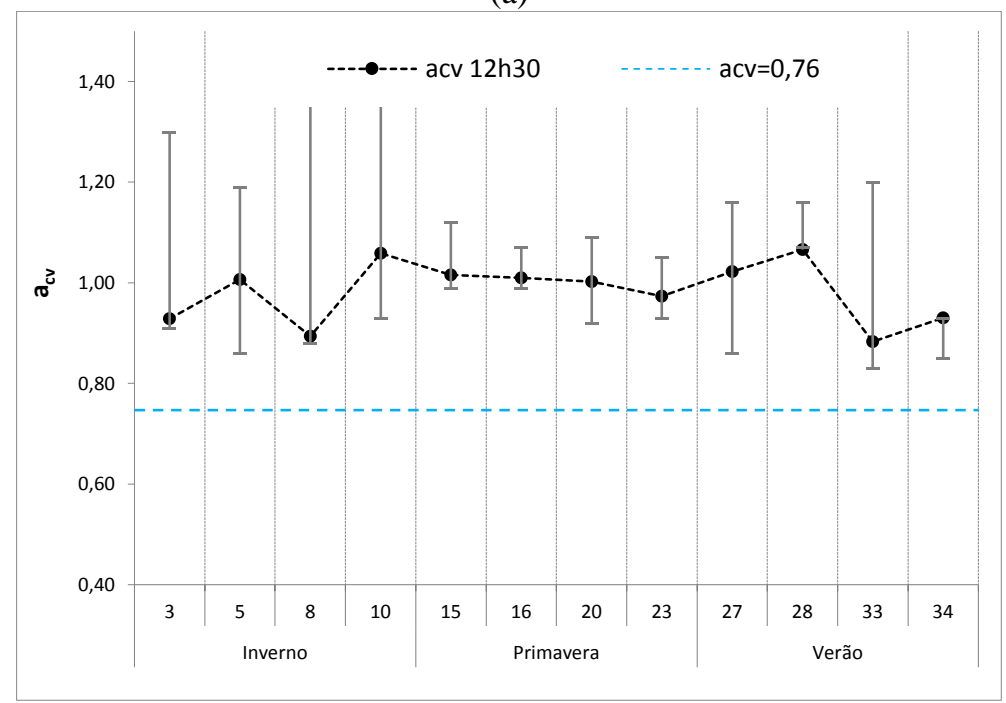

(b)

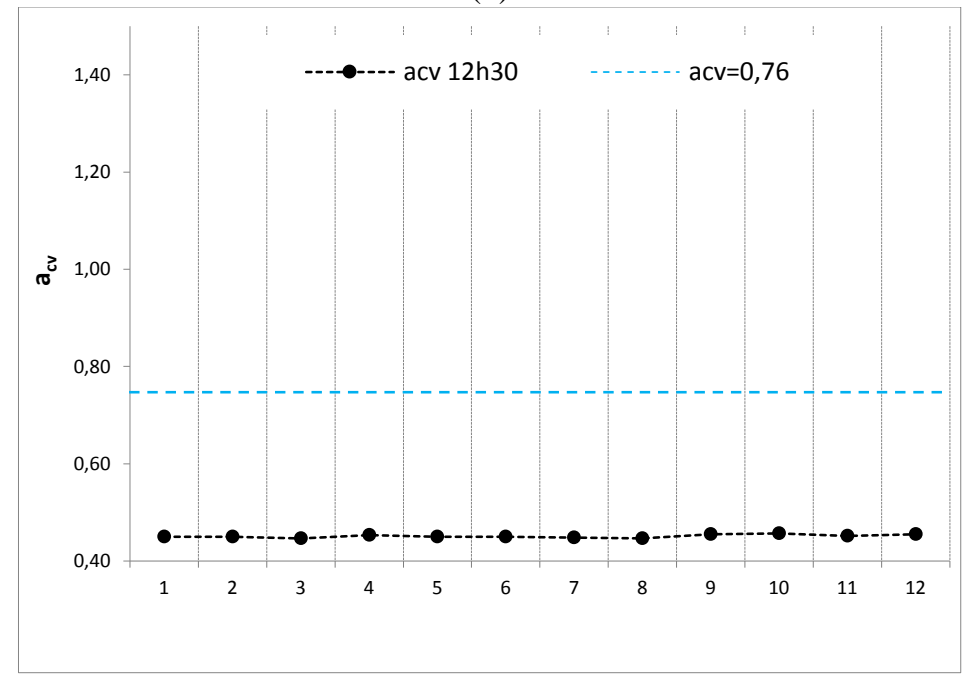

(c) 
Figura 8 - Valores médios de PMV registrados nos dois ambientes-testes ao longo de cada dia e às 12h30, horário de preenchimento dos questionários de avaliação subjetiva

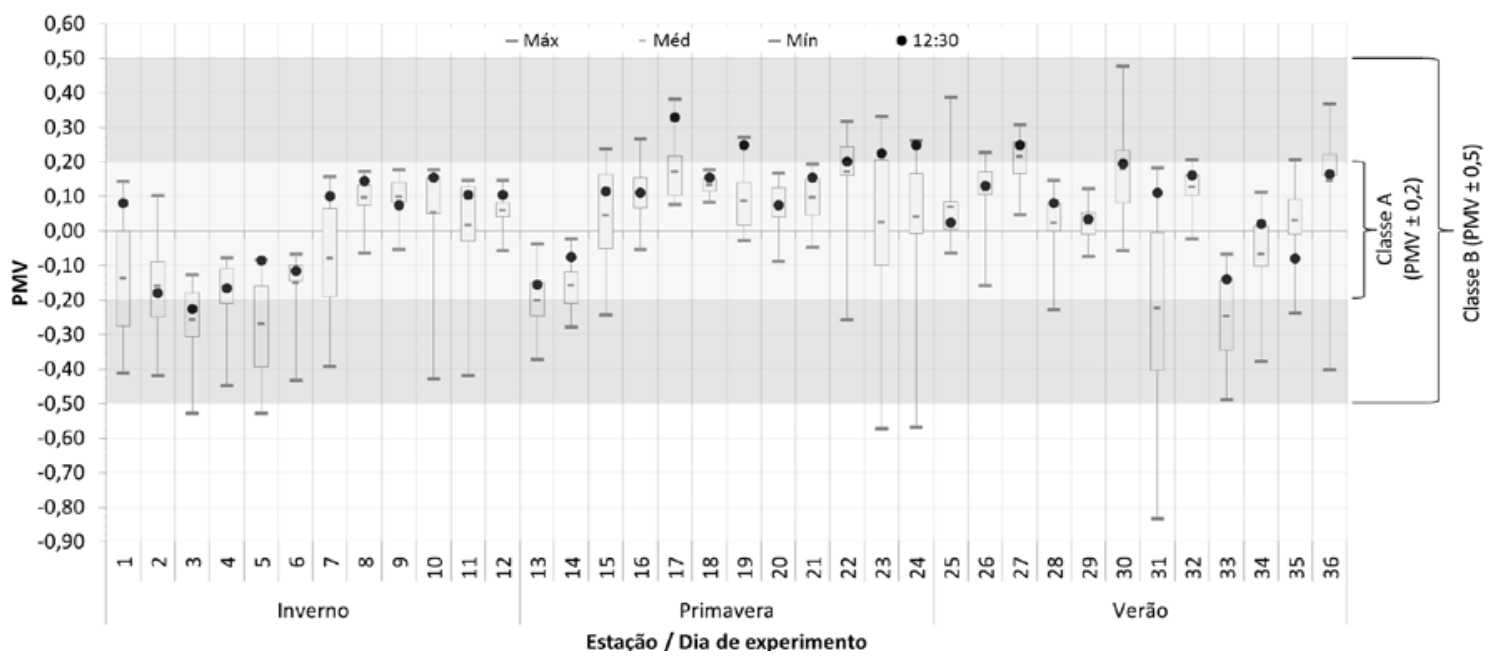

Observa-se que a maioria dos valores às $12 \mathrm{~h} 30$ (80\% das situações) permaneceu entre $0,2<\mathrm{PMV}<+0,2$, sendo 0 ambiente térmico categorizado segundo a norma EN ISO 7730 (INTERNATIONAL..., 2005) como Classe A. Nas demais situações, correspondentes a $20 \%$ do total, os participantes mantiveram-se na faixa de $0,5<$ PMV $<+0,5$, classificada pela mesma norma como Classe $\mathrm{B}$, ambas categorias de conforto térmico consideradas satisfatórias. Dessa forma, observa-se que a variável térmica, que esteve permanentemente dentro de faixas de conforto aceitáveis, pôde ser excluída como fator de influência às respostas subjetivas coletadas.

\section{Caracterização da amostra, variáveis subjetivas monitoradas e instrumentos de coleta}

A amostra foi composta de 16 indivíduos, estudantes alemães, homens, que participaram do experimento mediante remuneração. Esse tamanho é compatível com estudos correlatos. Em busca em junho de 2017 pelos termos "climatic+chamber" e "climate chamber" em artigos publicados entre 2012 e 2017 no repositório Web of Science, obtiveram-se 2.661 artigos que continham os dois termos pesquisados. Destes se identificaram 130 trabalhos cuja amostra foi composta de seres humanos, 122 dos quais citando o tamanho da amostra. O maior tamanho encontrado foi $n=124$, e o menor, $\mathrm{n}=3$. Do total, 8 estudos tiveram 16 indivíduos como amostra. O tamanho médio da amostra foi $n=21$, a moda de 10, e a mediana, 15 . Assim, verificou-se que o tamanho da amostra da presente pesquisa $(n=16)$ localiza-se na faixa onde há a maior concentração dos valores nas referências internacionais.
Todos os indivíduos foram selecionados arbitrariamente entre os candidatos que responderam a um anúncio veiculado no site do instituto proprietário da câmara climática (KIT). Excluiu-se a participação de indivíduos do sexo feminino a fim de se eliminarem vieses nos resultados.

Mulheres apresentam variações na temperatura corporal ao longo do período fértil. Baker et al. (2001) verificaram em estudo que tanto mulheres com ciclo ovulatório natural quanto mulheres que tomavam contraceptivos hormonais atingiram temperaturas corporais noturnas mínimas antes que os homens. Além disso, o mesmo trabalho verificou que as mulheres com ciclo natural possuíam a temperatura corporal noturna atenuada quando comparada à dos homens. Duffy et al. (2011) corroboram esses achados quando afirmam que os ritmos circadianos de produção de melatonina e temperatura corporal ocorrem mais cedo em mulheres do que em homens, mesmo quando ambos mantêm horários semelhantes e consistentes de dormir e acordar.

Além do comportamento térmico corporal, mulheres também apresentam sensibilidade à luz distinta da dos indivíduos do sexo masculino. Chellappa et al. (2017) encontraram diferenças entre os sexos relacionadas à percepção do brilho, à atenção e à fisiologia do sono quando expostos à luz vespertina azulada de 40 lux e $6.500 \mathrm{~K}$, ou amarelada, de $2.500 \mathrm{~K}$.

Os indivíduos que compuseram a amostra receberam aleatoriamente a codificação de 1 a 16 . Essa numeração foi posteriormente utilizada para definir a ocupação dos postos pelos indivíduos ao longo dos dias de experimento. A amostra apresentou os seguintes valores biométricos 
médios: altura 1,80 m ( $\sigma=0,06)$; massa corpórea 80 $\mathrm{kg}(\sigma=8,9)$ e idade 24,9 anos $(\sigma=3,6)$. Todos assinaram um termo de livre consentimento antes do início dos testes e foram informados sobre todos os procedimentos adotados, sobre o direito de interromperem a participação a qualquer momento e sobre a garantia de confidencialidade dos dados coletados. A pesquisa foi devidamente aprovada pelo Comitê de Ética do KIT.

Para a caracterização geral dos indivíduos, aplicouse anteriormente ao início dos testes e durante o primeiro dia de experimento uma série de questionários. Os critérios para a seleção dos instrumentos de coleta de dados foram:

(a) serem traduzidos e validados para o alemão;

(b) serem autoaplicáveis; e

(c) produzirem escores de classificação, dispensando acompanhamento direto de psicólogo na aplicação e avaliação dos resultados.

As variáveis subjetivas avaliadas relacionaram-se às condições de sono, como o cronotipo, sonolência diurna e qualidade do sono, bem-estar (ansiedade, estresse) e suscetibilidade a desordens afetivas sazonais. O preenchimento dos questionários foi on-line, em plataforma web desenvolvida para esse fim. Dado o escopo do trabalho, são aqui discutidas somente as avaliações:

(a) do cronotipo (realizada anteriormente ao início dos testes);

(b) da situação de luz; e

(c) da percepção térmica e luminosa, ambas realizadas todos os dias, às $12 \mathrm{~h} 30$, horário em que os indivíduos já estavam aclimatados às condições ambientais pré-configuradas para o dia.

Para a realização do teste correlacional, os dados foram agrupados em três grandes categorias quanto ao tipo de iluminação (natural, fachada equatorial Eq; natural, fachada não equatorial - Neq, e elétrica - Elét). Dentro de cada categoria testaram-se os dados isolados por estações (inverno, primavera e verão) e todas estas agrupadas. Esses testes foram realizados duas vezes: para a amostra total $(n=16)$ e somente para os indivíduos classificados com o cronotipo indiferente $(\mathrm{n}=11)$.

\section{Cronotipo}

Os ritmos de atividade-descanso podem variar entre indivíduos. Alguns preferem atividades matutinas, tendo facilidade em madrugar; outros são mais ativos à tarde ou à noite (LEHNKERING; SIEGMUND, 2007). À característica do indivíduo de apresentar períodos de maior e menor atividade em horários específicos dá-se o nome de cronotipo.
Essa característica, que é endógena e não passível de controle, pode influenciar na fisiologia térmica de indivíduos e consequentemente, em sua percepção térmica (RODEN; RUDNER; RAE, 2017). Kulve et al. (2016) verificaram que a luz vespertina (luz do período da tarde) pode reduzir a secreção de melatonina, atrasar o declínio natural da temperatura corporal (Core body temperature CBT) e diminuir a temperatura distal da pele. Contudo, durante a manhã a intensidade da luz pode resultar em um declínio mais rápido dos níveis de melatonina, o que permite aumento da CBT, ciclo que, no caso de indivíduos vespertinos, pode apresentar atraso (BAILEY; HEITKEMPER, 2001).

Horne e Östberg (1975) desenvolveram o Questionário de Identificação de Matutinos e Vespertinos (MEQ) (ou Morningness-eveningness questionnaire), aceito como o método mais fácil para determinar as preferências individuais relacionadas aos períodos de sono e vigília (LEHNKERING; SIEGMUND, 2007). O instrumento classifica indivíduos em três cronotipos: vespertino, matutino (extremo e moderado) e indiferente. O cronotipo não foi um critério no processo de seleção da amostra. Sendo assim, a frequência de cada tipo na amostra foi casual.

Quanto à avaliação do cronotipo da amostra, 5 indivíduos foram classificados como moderadamente vespertinos, e os demais como indiferentes. Sendo assim, para a análise correlacional, a amostra foi separada em dois grupos: todos os cronotipos $(n=16)$ e indiferentes $(n=11)$.

\section{Percepção lumínica do ambiente}

A percepção do ambiente em função das condições de iluminação foi quantificada com o uso de questionário elaborado com base no Questionário para Avaliação de Situações de Luz (EFI, Deutsche Lichttechnische Gesellschaft e.V., Expertenforum Innenbeleuchtung EFI) (VANDAHL; MOOSMAN; FUNKE, 2016). Esse instrumento contém nove questões relativas à percepção do ambiente; a pontuação é atribuída pelo indivíduo conforme a escala Likert numérica de sete pontos, cujos valores semânticos variam conforme a pergunta. O questionário levanta o grau de satisfação relacionado a variáveis como claridade, distribuição da luz e ofuscamento. No artigo, apenas o quesito percepção lumínica do ambiente foi analisado, conforme as duas questões e opções de resposta apresentadas no Quadro 3. 


\section{Percepção térmica}

A percepção térmica dos indivíduos foi registrada por meio da aplicação do Questionário de Percepção e Preferência Térmica, baseado na Norma ISO 10551 (INTERNATIONAL..., 1995). Composto de oito questões, também contém sete opções de resposta organizadas em uma escala do tipo Likert. Para o trabalho, somente os quesitos percepção da temperatura no posto de trabalho e no ambiente foram avaliados.

As duas questões e opções de resposta para este quesito são apresentadas no Quadro 4.

\section{Resultados}

Dada a natureza majoritariamente não paramétrica dos dados avaliados, verificada preliminarmente com a aplicação do teste de Shapiro-Wilk (LEOTTI; BIRCK; RIBOLDI, 2005), optou-se pela realização do cruzamento de dados objetivos (dados de iluminação) e subjetivos (percepção lumínica e térmica) por meio da aplicação do teste de correlação de Spearman $\left(\mathrm{r}_{\mathrm{s}}\right)$, realizada no software SPSS Statistics ${ }^{\circledR}$ 22, da IBM. As correlações significativas entre variáveis objetivas e subjetivas no nível $0,01(* *)$ e $0,05(*)^{9}$ encontradas para os dois grupos de cronotipo foram posteriormente tabuladas e são apresentadas respectivamente nas Tabelas 5 e 6 .

De forma a identificar isoladamente as correlações para cada uma das variáveis avaliadas, correlacionaram-se separadamente os dados de cada tipo de iluminação com cada uma das estações, e com o agrupamento de todas estas.

Na amostra total, que contemplou dados de todos os tipos de cronotipo ( $n=16$, Tabela 5), verificou-se a inexistência de correlações significativas tanto para a orientação equatorial (Eq), quanto para os períodos de primavera e verão, situações mais propícias à obtenção de insolação. Somente duas categorias de iluminação apresentaram resultados significativos: a iluminação elétrica (Elét) e a iluminação não equatorial (Neq).

\section{Quadro 3 - Questões para avaliação da percepção lumínica do ambiente e alternativas da escala Likert de sete pontos}

\begin{tabular}{|c|c|c|c|c|c|c|c|}
\hline \multicolumn{6}{|c|}{ Questão 4 - Q4: Como você percebe a iluminação neste momento em seu local de trabalho? } \\
Questão 6 - Q6: Como você percebe a iluminação neste momento na sala como um todo?
\end{tabular}

Quadro 4 - Questões para avaliação da percepção térmica e alternativas da escala Likert de sete pontos

\begin{tabular}{|c|c|c|c|c|c|c|c|}
\hline \multicolumn{6}{|c|}{ Questão 1 - Q1: Como você se sente no momento em relação à temperatura em seu local de trabalho? } \\
Questão 2 - Q2: Como você se sente no momento em relação à temperatura da sala? \\
\hline$-\mathbf{3}$ & $-\mathbf{2}$ & $\mathbf{- 1}$ & $\mathbf{0}$ & $\mathbf{1}$ & $\mathbf{2}$ & $\mathbf{3}$ & Não aplicável \\
\hline Muito frio & Frio & $\begin{array}{c}\text { Um pouco } \\
\text { frio }\end{array}$ & Neutro & $\begin{array}{c}\text { Um pouco } \\
\text { quente }\end{array}$ & Quente & $\begin{array}{c}\text { Muito } \\
\text { quente }\end{array}$ & Não sei dizer \\
\hline
\end{tabular}

Tabela 5 - Correlações Spearman $\left(r_{s}\right)$ entre variáveis objetivas e subjetivas identificadas para a amostra total $(n=16)$

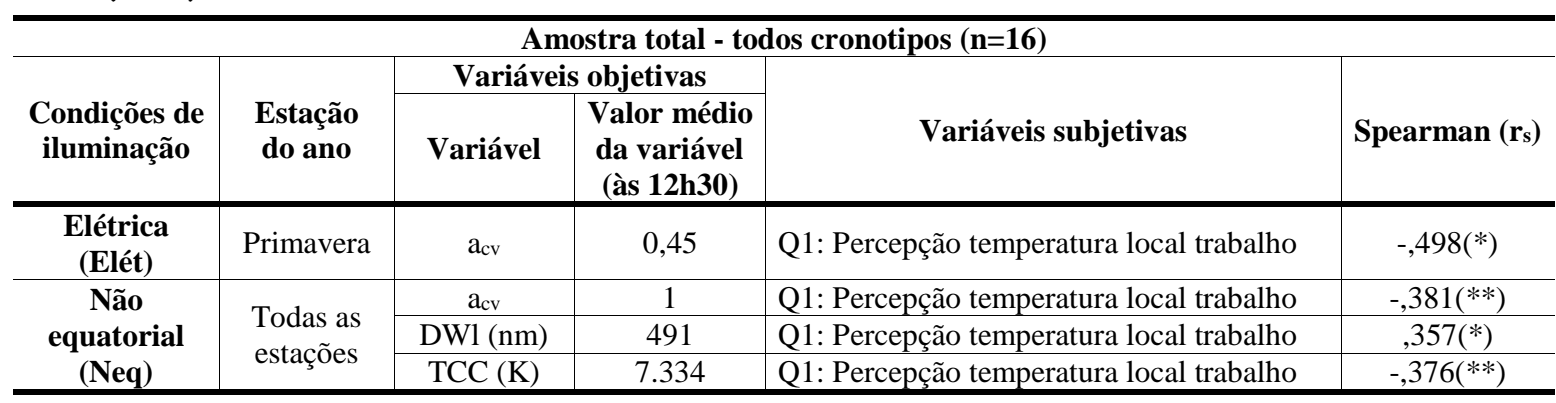

Nota: *A correlação é significativa no nível 0,05 (2 extremidades); e **A correlação é significativa no nível 0,01 (2 extremidades).

${ }_{9}^{9}$ robabilidade de que a correlação tenha sido encontrada ao acaso: $0,01(* *)=1 \%$ e $0,05(*)=5 \%$ 
É necessário frisar que a correlação encontrada na situação com iluminação elétrica (Elétr) se dá pelo tipo de iluminação, e não pela estação do ano (primavera), visto que nessas condições não houve contato dos indivíduos com o exterior. Essa relação inversa $\left(0,498\left(^{*}\right)\right)$ entre percepção da temperatura no local de trabalho (Q1) e o $\mathrm{a}_{\mathrm{cv}}$ indica que, quanto maior a sensação de frio proporcionada pela luz (>TCC) e quanto mais azulada ela for (< DWl), menos favorável será a percepção relacionada à temperatura no local de trabalho.

Correlações relativamente mais fracas foram obtidas para iluminação com orientação não equatorial (Neq). Somente a categoria com todas as estações apresentou correlações, ainda assim pouco significativas $(<0,5)$. Todas estas relacionaram a percepção da temperatura no local de trabalho (Questão1) com variáveis objetivas da iluminação: $\mathrm{a}_{\mathrm{cv}}\left(-0,381\left({ }^{* *}\right)\right)$; DWl (nm) $\left(0,357\left({ }^{*}\right)\right)$ e TCC $(\mathrm{K})(-$ $0,376(* *))$.

Quanto aos resultados obtidos com a amostra com o cronotipo indiferente ( $\mathrm{n}=11$, Tabela 6$)$, também se observou a inexistência de correlações para a Eq. O mesmo ocorreu para a iluminação Elét, havendo correlações somente para a situação de iluminação Neq. A única variável subjetiva que se relacionou significativamente com as condições de iluminação foi a Questão 1, “Como você se sente no momento em relação à temperatura em seu local de trabalho?”. Na categoria composta de todas as estações, esta questão correlacionou-se sucessivamente com $\mathrm{a}_{\mathrm{cv}-} 0,472(* *)$, DWl 0,452(*) e TCC -,465(**). A categoria inverno apresentou correlação significativa com as mesmas variáveis, com a mesma relação proporcional, mas com valores maiores: $\mathrm{a}_{\mathrm{cv}}-0,686(* *)$, DWl $0,686\left(^{*}\right)$ e TCC $-0,686(* *)$.
As correlações obtidas para a amostra com cronotipo indiferente, associadas às obtidas com a amostra total, reforçaram a possibilidade de que diferenciações na luz natural decorrentes da estação do ano podem alterar a percepção quanto à temperatura. A análise sem distinção entre inverno, primavera e verão resultou em valores correlacionais menores. No entanto, quando estes mesmos dados foram agrupados por estação, pôdese verificar que somente o inverno apresentou correlações significativas.

Nos dois grupos de cronotipos avaliados, observouse a inexistência de correlações entre valores de iluminância (lux) e aspectos de percepção, sejam térmicos ou de iluminação. Estão também ausentes correlações entre aspectos da iluminação e a percepção lumínica, tanto no local de trabalho (Questão 4), quanto no ambiente (Questão 6). Somente uma das duas questões que versavam sobre a percepção térmica, relacionada ao ambiente de trabalho (Q1), correlacionou-se com as demais variáveis objetivas de iluminação.

\section{Discussão}

O monitoramento e o controle da temperatura do ar nos ambientes-teste viabilizaram a manutenção do PMV entre +-0,5, Classe B de ambientes térmicos climatizados, conforme a norma EN ISO 7730 (INTERNATIONAL..., 2005). Dessa forma, excluiu-se o efeito térmico do ambiente nos indivíduos e consequentemente, nas respostas que levantavam a percepção térmica.

O registro das variáveis objetivas de iluminação para as três condições avaliadas (Eq, Neq e Elét) permitiu caracterizá-las e posteriormente correlacioná-las com a percepção térmica e lumínica.

Tabela 6 - Correlações Spearman $\left(r_{s}\right)$ entre variáveis objetivas e subjetivas identificadas para a amostra cronotipo indiferente $(\mathbf{n}=11)$

\begin{tabular}{|c|c|c|c|c|c|}
\hline \multicolumn{6}{|c|}{ Amostra cronotipo indiferente $(\mathrm{n}=11)$} \\
\hline \multirow[b]{2}{*}{$\begin{array}{l}\text { Condições } \\
\text { de } \\
\text { iluminação }\end{array}$} & \multirow[b]{2}{*}{$\begin{array}{c}\text { Estação } \\
\text { do ano }\end{array}$} & \multicolumn{2}{|c|}{ Variáveis objetivas } & \multirow[b]{2}{*}{ Variáveis subjetivas } & \multirow[b]{2}{*}{$\begin{array}{c}\text { Spearman } \\
\left(r_{s}\right)\end{array}$} \\
\hline & & Variável & $\begin{array}{c}\text { Valor } \\
\text { médio da } \\
\text { variável } \\
\text { (às 12h30) }\end{array}$ & & \\
\hline \multirow{6}{*}{$\begin{array}{c}\text { Não } \\
\text { equatorial } \\
\text { (Neq) }\end{array}$} & \multirow{3}{*}{$\begin{array}{l}\text { Todas as } \\
\text { estações }\end{array}$} & $\mathrm{a}_{\mathrm{cv}}$ & 1 & Q1: Percepção temperatura local trabalho & $0,472(* *)$ \\
\hline & & DWl (nm) & 491 & Q1: Percepção temperatura local trabalho & $0,452(*)$ \\
\hline & & TCC (K) & 7.334 & Q1: Percepção temperatura local trabalho & $0,465(* *)$ \\
\hline & \multirow{3}{*}{ Inverno } & $\mathrm{a}_{\mathrm{cv}}$ & 0,97 & Q1: Percepção temperatura local trabalho & $0,686(*)$ \\
\hline & & DWl (nm) & 492 & Q1: Percepção temperatura local trabalho & $0,686(*)$ \\
\hline & & TCC $(\mathrm{K})$ & 7.201 & Q1: Percepção temperatura local trabalho & $0,686(*)$ \\
\hline
\end{tabular}

Nota: *A correlação é significativa no nível 0,05 (2 extremidades); e **A correlação é significativa no nível 0,01 (2 extremidades). 
No caso da iluminação elétrica (Elét), as características registradas apresentaram-se desfavoráveis à sincronização circadiana. $\mathrm{O} \mathrm{a}_{\mathrm{cv}}$ manteve-se em 0,45 , a TCC apresentou-se neutra $(4.000 \mathrm{~K})$, e o DWl permaneceu estável na faixa amarela do espectro, o que corresponde à faixa de aparência quente da luz. A única correlação encontrada para a iluminação Elét foi para a amostra com todos os cronotipos, inversamente proporcional ao $\mathrm{a}_{\mathrm{cv}}$. Deve-se, porém, ressaltar que as condições físicas de iluminação elétrica pouco se alteraram durante o período de exposição, o que gerou menos discrepâncias nas respostas e, portanto, correlações potencialmente mais fortes, mas não necessariamente significativas.

Por outro lado, os valores médios registrados para as variáveis da iluminação natural equatorial (Eq) e não equatorial (Neq) apresentaram-se em faixas favoráveis à regulação circadiana. $\mathrm{O}$ fator de ação circadiano $\left(\mathrm{a}_{\mathrm{cv}}\right)$ manteve-se sempre acima de 0,76 , valor da métrica para insolação direta (GALL et al., 2004), adotada como referência neste estudo. A temperatura de cor correlata (TCC) manteve-se na porção de aparência azul, e o comprimento de onda na faixa azul do espectro, o que proporcionou aparência fria às situações com luz natural.

Não ocorreram correlações entre variáveis objetivas e subjetivas para a condição de iluminação equatorial (Eq), bem como para os períodos de primavera e verão. $\mathrm{O}$ fato parece conduzir para a hipótese de que a disponibilidade de luz pode influenciar no grau de sensibilidade de indivíduos em relação a ela. Assim, em situações ou períodos com alta oferta de iluminação (para ilustrar, o nascer e o pôr do sol no primeiro dia de teste de verão - 23 de junho - ocorreram às 5h22min e 21h34min respectivamente), a percepção dos indivíduos quanto a pequenas variações das condições de iluminação e temperatura pode ter sido sensivelmente reduzida. Por outro lado, dada a latitude onde se localiza a câmara climática, o início dos testes (8h00) durante o período de inverno ocorria antes do amanhecer. Nesta situação, no primeiro dia de testes (13 de janeiro), o nascer e o pôr do sol ocorreram respectivamente às $8 \mathrm{~h} 16 \mathrm{~min}$ e às 16h53min. Dessa forma, nessa situação os indivíduos da amostra permaneceram sob menor disponibilidade de luz, o que aparentemente poderia os tornar mais suscetíveis a pequenas variações dela, fazendo com que qualquer alteração fosse mais rápida e facilmente apreendida. No estudo em questão, essa maior sensibilidade se fez notar exclusivamente na percepção da temperatura do posto de trabalho para os dois grupos de cronotipo.

Para a iluminação Neq, a percepção da temperatura correlacionou-se diretamente com os valores de DWl, e inversamente com os valores de TCC e $\mathrm{a}_{\mathrm{cv}}$ nos dois grupos de cronotipo. Essas relações encontram suporte na literatura afim; no caso do DWl, a relação entre a exposição à iluminação natural cujo espectro de onda predominante (nm) durante o período da manhã é o azul, e sua direta relação com o processo de supressão da produção de melatonina e aumento da temperatura corporal é reconhecido (KÜLLER, 2002; WRIGHT; LACK; KENNAWAY, 2004; DIJK et al., 2012). Ademais, estudos indicam que fontes de iluminação com diferentes TCC podem influenciar a percepção de seres humanos quanto à sensação térmica em relação ao ambiente construído (CHAIN; DUMORTIER; FONTOYNONT, 2001; SHAMSUL et al., 2013; KULVE et al., 2016; HUEBNER et al., 2016).

Por fim, pontua-se que os valores de correlação para a amostra total $(n=16)$ mantiveram-se $<0,5$, enquanto para a amostra composta de sujeitos com o cronotipo indiferente $(n=11)$ estes valores mantiveram-se $>0,5$. Esse fato pode indicar que, para a amostra total com todos os cronotipos, a influência da iluminação natural no aumento da temperatura corporal matutina e, consequentemente, na percepção da temperatura pode ter sido mascarada pelo atraso de fase apresentado por indivíduos com cronotipo vespertino. Já no segundo grupo, composto somente de indivíduos com cronotipo indiferente, que apresentam o ciclo circadiano regular, essa influência pôde sem mais claramente identificada. Tal conclusão é suportada pelos trabalhos de Bailey e Heitkemper (2011) e Kelly (2007), entre outros.

No entanto, deve-se levantar uma segunda hipótese para a disparidade entre os grupos, relacionada à sensibilidade de testes estatísticos. Dependendo da distribuição e da natureza dos dados, estes podem vir a apresentar maiores valores correlacionais quanto menores forem as amostras. Cabe, assim, a devida cautela ao se analisar esse resultado (FIELD, 2009).

De forma a complementar a discussão dos resultados, o Quadro 5 apresenta sinteticamente os achados da pesquisa. 
Quadro 5 - Quadro resumo dos resultados obtidos

\begin{tabular}{|c|c|c|c|c|}
\hline \multirow[b]{2}{*}{$\begin{array}{c}\text { Tipo de } \\
\text { iluminação }\end{array}$} & \multirow[b]{2}{*}{ Estação } & \multirow[b]{2}{*}{$\begin{array}{l}\text { Variáveis } \\
\text { objetivas }\end{array}$} & \multicolumn{2}{|c|}{ Tipo de correlação } \\
\hline & & & $\begin{array}{c}\text { Sensação } \\
\text { térmica }\end{array}$ & $\begin{array}{l}\text { Sensação } \\
\text { lumínica }\end{array}$ \\
\hline \multirow{16}{*}{ 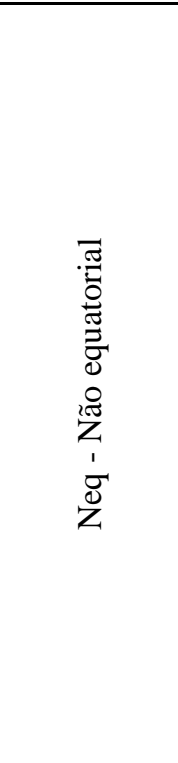 } & \multirow{4}{*}{ 怘 } & Eméd (lux) & $\begin{array}{c}\text { Sem } \\
\text { correlação }\end{array}$ & \multirow{4}{*}{$\begin{array}{c}\text { Sem } \\
\text { correlação }\end{array}$} \\
\hline & & TCC (K) & $\downarrow \uparrow$ & \\
\hline & & DWl (nm) & $\downarrow \downarrow$ & \\
\hline & & $\mathrm{a}_{\mathrm{cv}}$ & $\downarrow \uparrow$ & \\
\hline & \multirow{4}{*}{ 豞 } & Eméd (lux) & \multirow{4}{*}{\multicolumn{2}{|c|}{ Sem correlação }} \\
\hline & & TCC (K) & & \\
\hline & & DWl (nm) & & \\
\hline & & $\mathrm{aCV}$ & & \\
\hline & \multirow{4}{*}{ 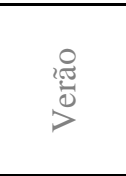 } & Eméd (lux) & \multirow{4}{*}{\multicolumn{2}{|c|}{ Sem correlação }} \\
\hline & & TCC $(\mathrm{K})$ & & \\
\hline & & DWl (nm) & & \\
\hline & & acV & & \\
\hline & \multirow{4}{*}{$\underset{\tilde{D}}{\tilde{z}}$} & Eméd (lux) & $\begin{array}{c}\text { Sem } \\
\text { correlação }\end{array}$ & \multirow{4}{*}{$\begin{array}{c}\text { Sem } \\
\text { correlação }\end{array}$} \\
\hline & & TCC (K) & $\downarrow \uparrow$ & \\
\hline & & DWl (nm) & $\downarrow \downarrow$ & \\
\hline & & $\mathrm{a}_{\mathrm{cv}}$ & $\downarrow \uparrow$ & \\
\hline \multirow{4}{*}{ 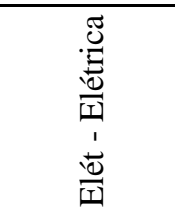 } & \multirow{4}{*}{$\stackrel{*}{\stackrel{*}{Z}}$} & Eméd (lux) & \multirow{3}{*}{\multicolumn{2}{|c|}{ Sem correlação }} \\
\hline & & TCC (K) & & \\
\hline & & DWl (nm) & & \\
\hline & & $\mathrm{a}_{\mathrm{cv}}$ & $\downarrow \uparrow$ & $\begin{array}{c}\text { Sem } \\
\text { correlação }\end{array}$ \\
\hline
\end{tabular}

Nota: Legenda:

$$
\begin{aligned}
& \downarrow \downarrow=A \text { correlação é direta; } \\
& \downarrow \uparrow=A \text { correlação é inversa; e } \\
& { }^{*} \text { A estação não se aplica. }
\end{aligned}
$$

\section{Conclusões}

Ainda que o conforto visual, ligado à execução de tarefas visuais, não tenha sido o foco deste trabalho, a inclusão da iluminância (E) da superfície de trabalho na análise foi válida. Isso permitiu verificar que essa variável não teve influência na percepção lumínica ou térmica da amostra avaliada sob as condições em que o experimento foi realizado. Esse resultado leva à reflexão de que as normatizações atuais que versam sobre a intensidade e o tempo de exposição a valores de iluminância podem atender a necessidades visuais, mas não a demandas pessoais ou fisiológicas.

Não se registrou neste experimento qualquer correlação entre a percepção lumínica do ambiente e a temperatura de cor (TCC), o comprimento de onda dominante (DWl) ou o fator de ação circadiano $\left(\mathrm{a}_{\mathrm{cv}}\right)$. Essas variáveis, por sua vez, correlacionaram-se somente com a percepção da temperatura no posto de trabalho, levantada pela questão 1 do Questionário de Percepção e Preferência Térmica. Para a amostra total com todos os cronotipos $(n=16)$, essa relação de dependência foi identificada somente na situação de iluminação não equatorial (Neq) para a categoria composta pelos resultados das três estações avaliadas agrupadas. Também no caso do grupo constituído por indivíduos com o cronotipo normal $(n=11)$, identificaram-se correlações significativas somente na situação de iluminação Neq. Para os dois grupos de cronotipo, as correlações obtidas permitiram observar que a adequação das características da iluminação à promoção da sincronização circadiana esteve inversamente relacionada à satisfação dos indivíduos quanto às características térmicas do ambiente de trabalho, com níveis de significância menores no grupo total, e maiores no grupo com cronotipo indiferente. Esse resultado pode indicar a necessidade da composição de sistemas mistos de iluminação em projetos luminotécnicos, de forma que demandas visuais, não visuais e relacionadas à percepção possam ser igualmente contempladas.

Ante os resultados obtidos e a leitura da bibliografia consultada, frisa-se que o campo de estudo que relaciona os efeitos da luz na sensação térmica e no conforto de indivíduos permanece em construção, não sendo ainda possível inferir com alto grau de 
confiabilidade qualquer conclusão. A pesquisa, que apresenta como principais limitações uma amostra reduzida e sua seleção não probabilística, impede a generalização dos resultados, buscando apenas colaborar timidamente com a expansão desse campo do conhecimento ao apontar limitações e lacunas a serem ainda discutidas e futuramente preenchidas pela comunidade científica.

\section{Referências}

ANDERSON, J. L. et al. Lux vs. Wavelength in Light Treatment of Seasonal Affective Disorder. Acta Psychiatrica Scandinavica, v. 120, n. 3, p. 203-212, 2009.

BAILEY, S. L.; HEITKEMPER, M. M. Circadian Rhythmicity of Cortisol and Body Temperature: morningness-eveningness effects. Chronobiology International, v. 18, n. 2, p. 249-261, 2001.

BAKER, F. C. et al. Sleep and 24 Hour Body Temperatures: a comparison in young men, naturally cycling women and women taking hormonal contraceptives. The Journal of Physiology, v. 530, n. 3, p. 565-574, 2001.

BARKMANN, C.; WESSOLOWSKI, N.; SCHULTE-MARKWORT, M. Applicability and Efficacy of Variable Light in Schools. Physiology \& Behavior, v. 105, n. 3, p. 621-627, 2012.

BEUTE, F.; DE KORT, Y. A. Let the Sun Shine! Measuring explicit and implicit preference for environments differing in naturalness, weather type and brightness. Journal of Environmental Psychology, v. 36, p. 162-178, 2013.

BRAINARD, G. C. et al. Action Spectrum For Melatonin Regulation in Humans: evidence for a novel circadian photoreceptor. Journal of Neuroscience, v. 21, n. 16, p. 6405-6412, 2001.

CAJOCHEN, C. Alerting Effects of Light. Sleep Medicine Reviews, v. 11, n. 6, p. 453-464, 2007.

CHAIN, C.; DUMORTIER, D.; FONTOYNONT, M. Consideration of Daylight's Colour. Energy and Buildings, v. 33, n. 3, p. 193-198, 2001.

CHELLAPPA, S. L. et al. Non-Visual Effects of Light on Melatonin, Alertness and Cognitive Performance: can blue-enriched light keep us alert? PloS one, v. 6, n. 1, p. e16429, 2011.

CHELLAPPA, S. L. et al. Sex Differences in Light Sensitivity Impact on Brightness Perception, Vigilant Attention and Sleep in Humans. Nature Scientific Reports, v. 6, n. 14217, 2017.
COMMISSION INTERNATIONALE DE L'ECLAIRAGE. CIE Research Strategy. Viena, ago. 2016. Disponível em:

$<$ http://www.cie.co.at/index.php/Research+Strateg y>. Acesso em: 9 out. 2017.

DESPENIC, M. et al. Lighting Preference Profiles of Users in an Open Office Environment. Building and Environment, v. 116, p. 89-107, 2017.

DEUTSCHES INSTITUT FÜR NORMUNG. DIN 5034: Tageslicht in Innenräumen. Berlin, 1997.

DEUTSCHES INSTITUT FÜR NORMUNG. DIN 6169-2: Farbwiedergabe: teil 2: FarbwiedergabeEigenschaften von Lichtquellen in der Beleuchtungstechnik. Berlin, 2002.

DEUTSCHES INSTITUT FÜR NORMUNG. DIN V5031-5100: Strahlungsphysik im optischen Bereich und Lichttechnik - Teil 100: Über das Auge vermittelte, nichtvisuelle Wirkung des Lichts auf den Menschen e Grössen, Formelzeichen und Wirkungsspektren. Berlin, 2009.

DIETRICH, G.; BIESKE, K. Definition and Measurement of Circadian Radiometric Quantities. In: CIE SYMPOSIUM'04 ON LIGHT AND HEALTH, 2004. Proceedings... 2004.

DIJK, D. D. et al. Amplitude Reduction and Phase Shifts of Melatonin, Cortisol and Other Circadian Rhythms After a Gradual Advance of Sleep and Light Exposure in Humans. PloS one, v. 7, n. 2, p. e30037, 2012.

DUFFY, J. F. et al. Sex Difference in the Near-24Hour Intrinsic Period of the Human Circadian Timing System. Proceedings of the National Academy of Sciences, v. 108, n. Supplement 3, p. 15602-15608, 2011.

EAGLES, J. M. Light Therapy and Seasonal Affective Disorder. Psychiatry, v. 8, n. 4, p. 125129, 2009.

\section{ELETROBRÁS; PROCEL. Manual de}

Iluminação. Rio de Janeiro, 2011. Disponível em: <http://www.mme.gov.br/documents/10584/19852 41/MANUAL\%20DE\%20ILUMINACAO\%20\%20PROCEL_EPP\%20-AGOSTO\%202011.pdf>. Acesso em: 4 mar. 2017.

FANGER, P. O. Assessment of Man's Thermal Comfort in Practice. British Journal of Industrial Medicine, v. 30, n. 4, p. 313-324, 1973.

FARIA, J. R. G. D.; INSKAVA, A. Y.; PLANITZER, S. T. Lighting Preferences in Individual Offices. Ambiente Construído, Porto Alegre, v. 17, n. 1, p. 39-53, jan./mar. 2017.

FIELD, A. Discovering Statistics Using SPSS. London: Sage, 2009. 
GALASIU, A. D.; VEITCH, J. A. Occupant preferences and satisfaction with the luminous environment and control systems in daylit offices: a literature review. Energy and Buildings, v. 38, n. 7, p. 728-742, 2006.

GALL, D. et al. Die Ermittlung von Licht-und Farbfeldgrößen zur Bestimmung der spektralen Wirkung des Lichtes. Technische Universität Ilmenau, Fachgebiet Lichttechnik, 2004.

HORNE, J. A.; ÖSTBERG, O. A Self-Assessment Questionnaire to Determine MorningnessEveningness in Human Circadian Rhythms. International Journal of Chronobiology, v. 4, n. 2, p. 97-110, 1975.

HRASKA, J. Chronobiological Aspects of Green Buildings Daylighting. Renewable Energy, v. 73, p. 109-114, 2015.

HUBALEK, S.; BRINK, M.; SCHIERZ, C. Office Worker's Daily Exposure to Light and its Influence on Sleep Quality and Mood. Lighting Research and Technology, v. 42, n. 1, p. 33-50, 2010.

HUEBNER, G. M. et al. Feeling the Light? Impact of illumination on observed thermal comfort. In: EXPERIENCING LIGHT, 2014. Proceedings..., 2014.

HUEBNER, G. M. et al. Saving Energy With Light? Experimental studies assessing the impact of colour temperature on thermal comfort. Energy Research \& Social Science, v. 15, p. 45-57, 2016.

INTERNATIONAL ORGANISATION FOR STANDARDISATION. EN ISO 7730:

ergonomics of the thermal environment: analytical determination and interpretation of thermal comfort using calculation of the PMV and PPD indices and local thermal comfort criteria. Geneva, 2005.

\section{INTERNATIONAL ORGANISATION FOR} STANDARDISATION. ISO 10551: ergonomics of the Thermal Environment: assessment of the influence the thermal environment using subjective judgement scales. Geneva, 1995.

KARATSOREOS, I. N. Effects of Circadian Disruption on Mental and Physical Health. Current Neurology and Neuroscience Reports, v. 12, n. 2, p. 218-225, 2012.

KAYA, S. M.; AFACAN, Y. Effects of Daylight Design Features on Visitors' Satisfaction of Museums. Indoor and Built Environment, v. 22, p. 822-835, apr. 2017.
KELLY, G. S. Body Temperature Variability (Part 2): masking influences of body temperature variability and a review of body temperature variability in disease. Alternative Medicine Review, v. 12, n. 1, p. 49-62, 2007.

KÜLLER, R. The Influence of Light on Circarhythms in Humans. Journal of Physiological Anthropology and Applied Human Science, v. 21, n. 2, p. 87-91, 2002.

KULVE, M. et al. The Influence of Light on Thermal Responses. Acta Physiologica, v. 216, n. 2, p. 163-185, 2016.

LEHNKERING, H.; SIEGMUND, R. Influence of Chronotype, Season, and Sex of Subject on Sleep Behavior of Young Adults. Chronobiology International, v. 24, n. 5, p. 875-888, 2007.

LEOTTI, V. B.; BIRCK, A. R.; RIBOLDI, J. Comparação dos Testes de Aderência à Normalidade Kolmogorov-Smirnov, AndersonDarling, Cramer-Von Mises e Shapiro-Wilk por simulação. Simpósio de Estatística Aplicada à Experimentação Agronômica, v. 11, p. 192, 2005.

NAKAMURA, H.; OKI, M. Influence of Air Temperature on Preference For Color Temperature of General Lighting in the Room. Journal of the Human-Environment System, v. 4, n. 1, p. 4147, 2000.

OSRAM. Product Family Datasheet Lumilux T8. 2018. Disponível em: <https://www.osramlamps.com/ecatalog/lamps/fluorescentlamps/fluorescent-lamps-t8/lumilux-t8/index.jsp>. Acesso em: 6 fev. 2018.

RODEN, L. C.; RUDNER, T. D.; RAE, D. E. Impact of Chronotype on Athletic Performance: current perspectives. ChronoPhysiology and Terapy, v. 7, p. 1-6, 2017.

SCHWEIKER, M. et al. Presenting LOBSTER, an Innovative Climate Chamber, and the Analysis of the Effect of a Ceiling Fan on the Thermal Sensation and Performance Under Summer Conditions in an Office-Like Setting. In: WINDSOR CONFERENCE: COUNTING THE COST OF COMFORT IN A CHANGING WORLD, 8., Windsor, 2014. Proceedings... Windsor, 2014.

SHAMSUL, B. M. T. Effects of Light's Colour Temperatures on Visual Comfort Level, Task Performances, and Alertness Among Students. American Journal of Public Health Research, v. 1, n. 7, p. 159-165, 2013.

SILVESTER, J.; KONSTANTINOU, E. Lighting, Well-Being and Performance at Work. Londres: City University, 2010. 
STIDSEN L.; BJERRUM H.; KIRKEGAARD, P. Patients' Light Preferences in Hospital Wards: related to light atmosphere in Danish homes. In: INTERNATIONAL CONFERENCE ON LIGHT 2011, Proceedings... Wessex: Wessex Institute of Technology, 2011.

THAPAN, K.; ARENDT, J.; SKENE, D. J. An Action Spectrum for Melatonin Suppression: evidence for a novel non-rod, non-cone photoreceptor system in humans. The Journal of Physiology, v. 535, n. 1, p. 261-267, 2001.

THORNE, H. C. et al. Daily and Seasonal variation in the Spectral Composition of Light Exposure in Humans. Chronobiology

International, v. 26, n. 5, p. 854-866, 2009.

VANDAHL, C.; MOOSMANN, C.; FUNKE, C. Uniform Assessment of Lighting Situations With the LiTG Questionnaire: first experiences. In: LICHT 2016, Karlsruhe, 2016. Proceedings... Karlsruhe, 2016.
WEISS, T.; KRÜGER, E. L.; TAMURA, C. A. Uso de Simulação Computacional Como Suporte a Um Estudo de Iluminação Natural em Câmara Climática. In: ENCONTRO NACIONAL, 13.; ENCONTRO LATINO-AMERICANO DE CONFORTO NO AMBIENTE CONSTRUÍDO, 9., Campinas, 2015. Anais... Campinas, 2015.

WRIGHT, H. R.; LACK, L. C.; KENNAWAY, D. J. Differential Effects of Light Wavelength in Phase Advancing the Melatonin Rhythm. Journal of Pineal Research, v. 36, n. 2, p. 140-144, 2004.

ZHONG, X. et al. Influence of Illumination Level on Visual Fatigue and Lighting Preference for Different Age Groups in China. SID Symposium Digest of Technical Papers, v. 48, n. 1, p. 18081811, 2017.

\section{Agradecimentos}

Os autores agradecem ao CNPq pela concessão de bolsa Pós-Doutorado Júnior (PDJ) e a todos os indivíduos que compuseram a amostra.

Revista Ambiente Construído

Associação Nacional de Tecnologia do Ambiente Construído

Av. Osvaldo Aranha, 99 - 3o andar, Centro

Porto Alegre - RS - Brasil CEP $90035-190$

Telefone: +55 (51) 3308-4084

Fax: +55 (51) 3308-4054

www. seer. ufrgs. br/ ambienteconstruido

E-mail: ambienteconstruido@ufrgs.br

This is an open-access article distributed under the terms of the Creative Commons Attribution License. 